Spring 4-24-2020

\title{
Occupational Therapy Student Pro Bono Clinic: Creating a Sustainable Model
}

\section{Shane Tong}

University of St. Augustine for Health Sciences

DOI: https://doi.org/10.46409/sr.BVEX9513

Follow this and additional works at: https://soar.usa.edu/capstones

Part of the Health and Medical Administration Commons, Medical Education Commons, and the Occupational Therapy Commons

\section{Recommended Citation}

Tong, S. (2020). Occupational Therapy Student Pro Bono Clinic: Creating a Sustainable Model. [Doctoral project, University of St Augustine for Health Sciences]. SOAR @ USA: Student Capstone Projects Collection. https://doi.org/10.46409/sr.BVEX9513

This Capstone is brought to you for free and open access by the Student Research at SOAR @ USA. It has been accepted for inclusion in Student Capstone Projects by an authorized administrator of SOAR @ USA. For more information, please contact soar@usa.edu, erobinson@usa.edu. 
OCCUPATIONAL THERAPY STUDENT PRO BONO CLINIC: CREATING A SUSTAINABLE MODEL

by

Shane S. Tong

\begin{abstract}
A Capstone Presented in Partial Fulfillment
of the Requirement for the Degree of DOCTOR OF OCCUPATIONAL THERAPY

University of St. Augustine for Health Sciences
\end{abstract}

April, 2020 
OCCUPATIONAL THERAPY STUDENT PRO BONO CLINIC: CREATING A

SUSTAINABLE MODEL

by

Shane S. Tong

has been approved

April, 2020

APPROVED:

Kayla Collins, EdD, OTR/L, Doctoral Coordinator

Thais Petrocelli, OTD, OTR/L, Doctoral Coordinator

Mary Shotwell, PhD, OT/L, Program Director

ACCEPTED AND SIGNED:

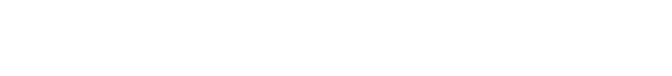

Kayla Collins, EdD, OTR/L, Doctoral Coordinator

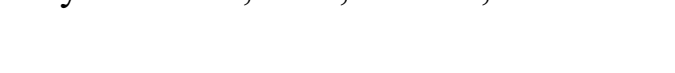

email=tpetrocellieusa.edu, $c=$ US
Date: 2020.07.29 14:35:58-0400'

Thais Petrocelli, OTD, OTR/L, Doctoral Coordinator

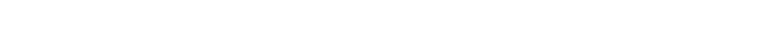

OT/L, FAOTA
Mary Shotwell, PhD, OT/L, Program Director 


\section{Table of Contents}

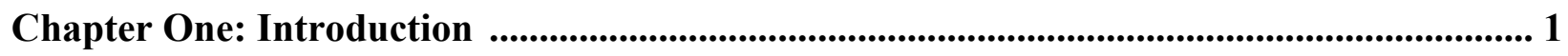

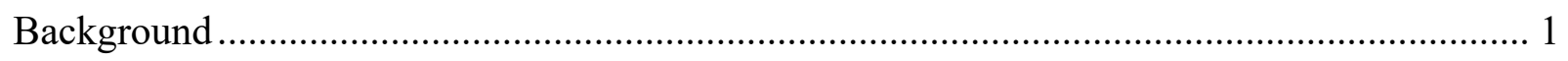

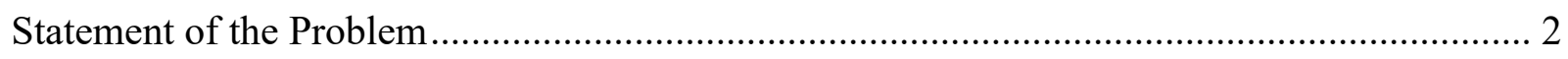

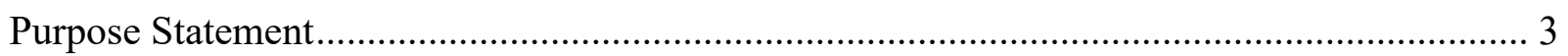

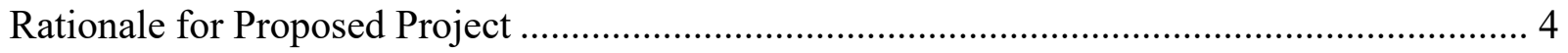

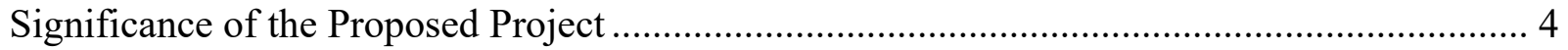

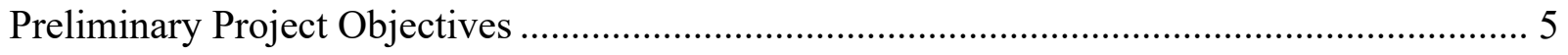

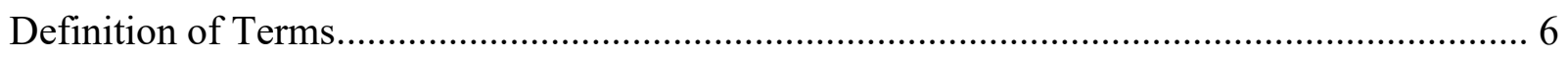

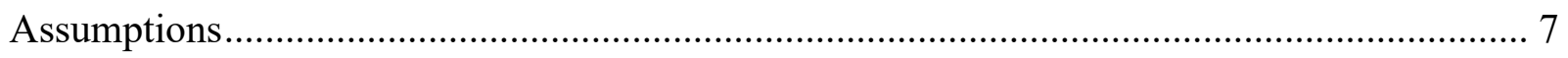

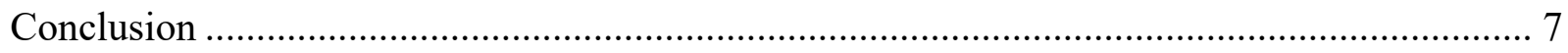

Chapter Two: Literature Review ..................................................................................................... 9

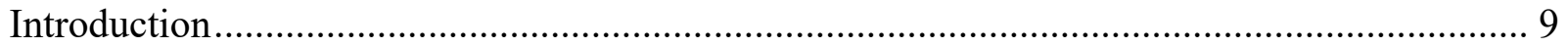

Benefits of Hands-on Practice for Health Care Students .................................................... 9

Student Impact of Pro Bono Clinics ............................................................................ 10

University Impact of Pro Bono Clinics......................................................................... 12

Unique Opportunity for Fieldwork Experience ......................................................... 13

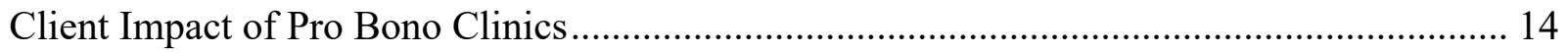

Developing a Pro Bono Clinic ....................................................................................... 16

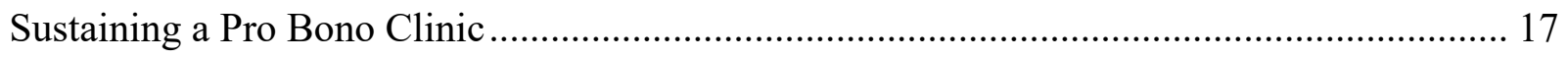

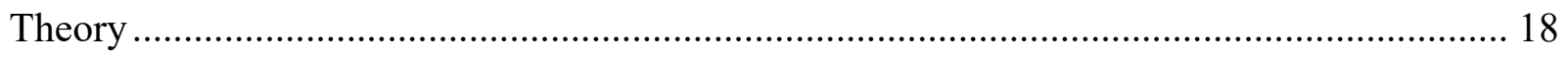

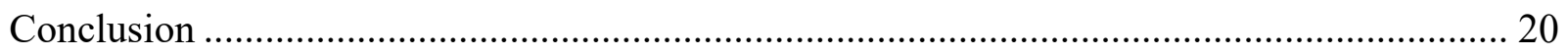

Chapter Three: Project Description................................................................................................... 21

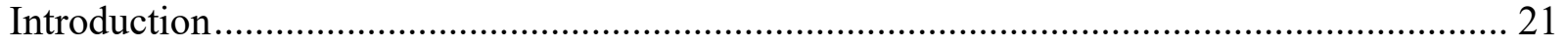

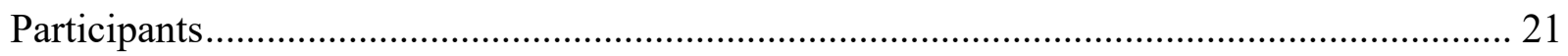

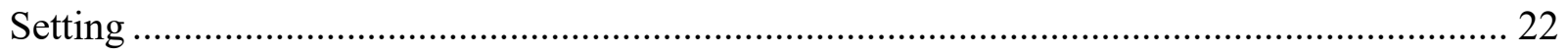

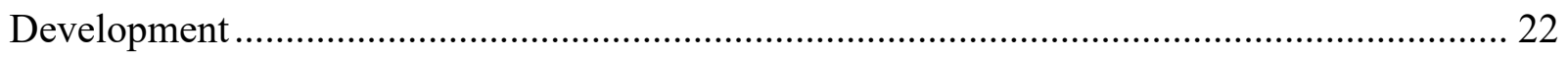

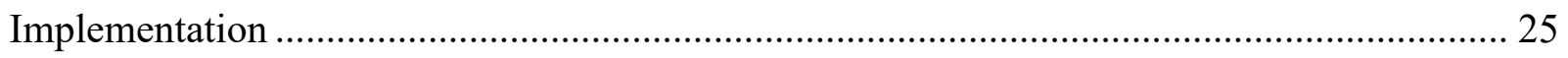

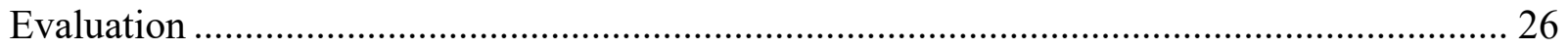

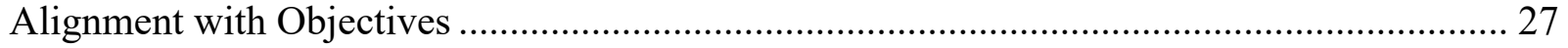

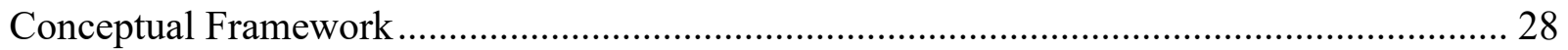

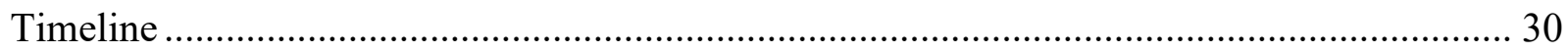




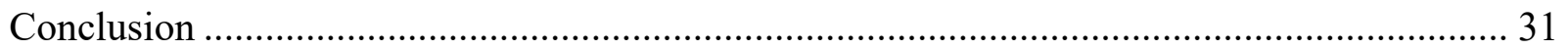

Chapter Four: Results .................................................................................................................... 32

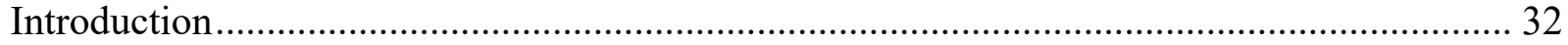

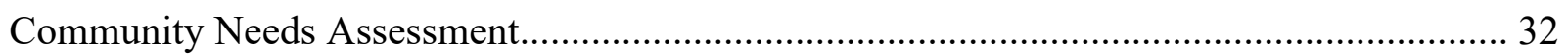

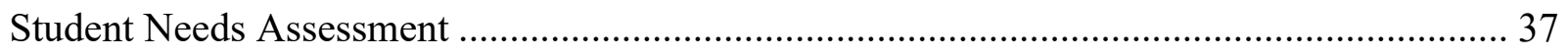

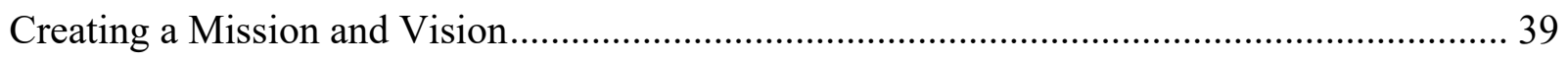

Investigation of Best Practices......................................................................................... 40

Student Leadership Development ...................................................................................... 43

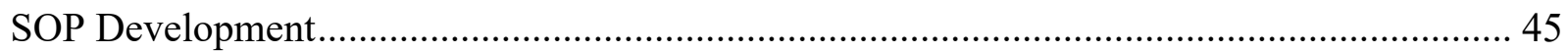

Assessing Effectiveness ............................................................................................... 47

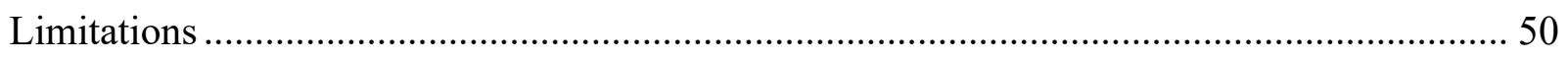

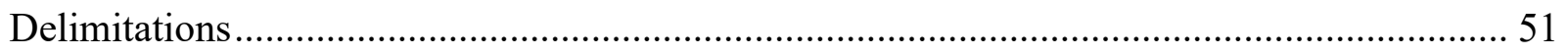

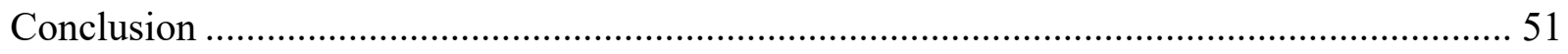

Chapter Five: Summary .................................................................................................................... 53

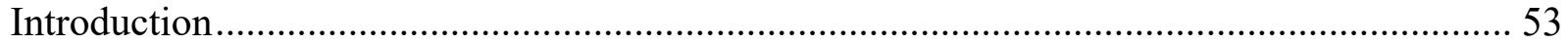

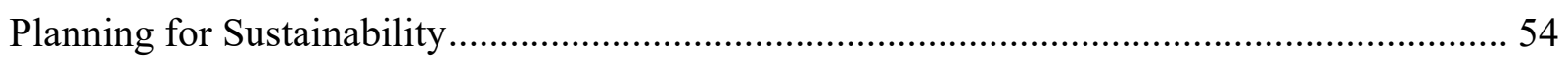

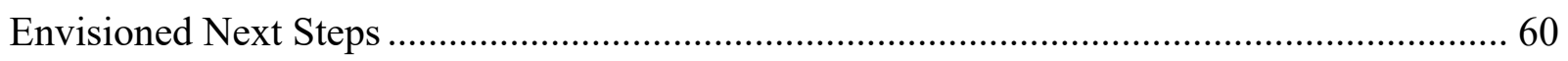

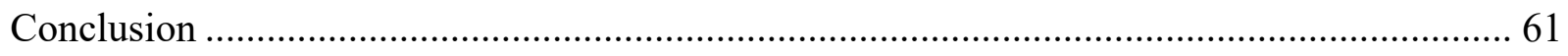

References..................................................................................................................................... 63

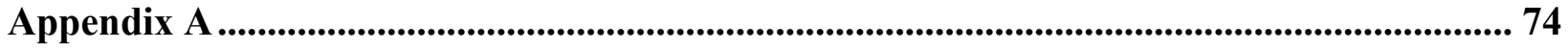

\section{List of Tables}

Table 1: Demographics of St. Johns and Surrounding Counties ............................................... 34

Table 2: 2018-2020 Strategic Objectives for St. Johns County, FL ........................................... 36

\section{List of Figures}

Figure 1: Clinic Organizational Chart. 


\section{Chapter 1: Introduction}

This capstone project was intended to provide universities with Occupational Therapy (OT) programs a sustainable model for planning and operating a student pro bono clinic. These community-based programs have the potential to benefit students, clients, the community, and the university. A student pro bono clinic should be developed strategically to ensure its sustainability and to optimize the benefits for all stakeholders.

\section{Background}

The OT profession is guided by the American Occupational Therapy Association's (AOTA) Code of Ethics (2015), which outlines core values, principles, and standards of conduct. The first core value listed in the document is altruism, emphasizing the importance of the OT profession in caring for the well-being of others. Principle 4 of the Code of Ethics, Justice, describes that occupational therapy professionals should promote a society where there is equal access to participate in meaningful occupations (AOTA, 2015). Further, it suggests that clients with barriers to accessing OT services be referred to charity care or pro bono services. Offering care to the underserved in the community demonstrates a professional commitment and dedication to improving the ability for all to function in their desired occupations.

By connecting the community with student therapists through university-sponsored pro bono clinics, a relationship is formed that benefits clients, students, the university, and the community. These programs provide an excellent opportunity for students to practice clinical reasoning and interprofessional skills (Sief et al., 2014). Additionally, Hallin, Kiessling, Walder, and Henriksson (2009) found that working with clients in an interprofessional setting led to a significant increase in OT student's self-confidence in interactions with other health care disciplines, which is a necessary skill in most fieldwork settings. 
During the didactic portion of the OT curriculum, students are required to complete Level I fieldwork hours. The AOTA suggests Level I hours are intended to introduce the fieldwork experience: "[they] enrich didactic coursework through directed observation and participation in selected aspects of the occupational therapy process" (“Level I Fieldwork”, 2019, para. 1). Level I fieldwork experiences are critical because they support the transition from classroom knowledge to clinical practice. However, Rodger et al. (2007) explains that, across the allied health professions, finding Level I fieldwork placements is a hurdle that many universities face. This challenge has created a search for alternative fieldwork opportunities, leading to an increase in the use of simulated learning experiences (SLE) and student pro bono clinics.

In looking at similar clinics started by academic institutions, it is evident that student pro bono clinics often face barriers to sustainability. Rockhurst University, which offers pro bono physical therapy (PT) and OT services in the Kansas City, Missouri, area, has reported a cancellation rate of up to $50 \%$ due to challenges experienced by the underserved community (Delahunt, Wisdom, Swift, \& Siscos, 2018). It is, therefore, incumbent upon programs that wish to start a pro bono clinic to utilize a strategic model as a guideline for the development and implementation of a sustainable community program.

\section{Statement of Problem}

As reported by George et al. (2017), student pro bono clinics are a way to provide muchneeded care to the community while allowing students to refine their clinical, communication, administrative, and interprofessional skills. The benefits of pro bono clinics for students and clients across health care disciplines have been established, and while there is a fair amount of research on the development of student pro bono clinics by other medical professions, the availability of such information OT-specific clinics is sparse. However, a relevant opinion piece 
was utilized. Gaffney (2019) offered 12 steps to consider when starting a student pro bono OT clinic, which were reflected in the model development for the clinic described in this capstone manuscript. While these recommendations are helpful, the occupational therapy profession needs a consistent theory-based, strategic approach for operating pro bono clinics. The development of a model will ensure that each student, university, client, and community reaps the benefits without succumbing to the challenges.

\section{Purpose Statement}

The purpose of this capstone project was to create a model for a sustainable student pro bono clinic with a clear mission and vision that aligned with that of the OT profession. This project consisted of conducting a needs assessment, as well as a strengths, weaknesses, opportunities, and threats (SWOT) analysis (Blayney, 2008) of current pro bono clinic operations at the University of St. Augustine College for Health Sciences (USAHS). These results, combined with input from key stakeholders, were used to develop a strategic plan focused on the OT pro bono operations, and to align the OT and PT initiatives to maximize the potential for interdisciplinary collaboration and community benefit.

The only example of an OT specific clinic found in a literature search was at the University of Tennessee Health Science Center (UTHSC). This program focused on helping the community by offering pediatric services to the underserved (Zachry, Allen, Dickey, \& Moore, 2016). Therefore, the principal investigator interviewed founding members of successful university-sponsored pro bono clinics serving the adult population to identify best practices. These insights informed the development of the USAHS clinic. They could also support the development of future pro bono clinics by OT programs across the nation. 


\section{Rationale for Proposed Project}

OT literature emphasizes the concept of occupational justice, which refers to a societal obligation to ensure that people have access to occupational opportunities (Braveman \& BassHaugen, 2009). Those with disabilities or with inadequate health insurance are at an increased likelihood of facing barriers that restrict their participation in the community and in employment, which further limits their access to resources such as OT (Braveman \& Suarez-Balcazar, 2009). Creating a strategic model for operating a pro bono clinic will allow for the sustainable provision of a community-based program that provides occupational justice to clients. The clinic will also help to prepare students for clinical practice and offers universities a means of delivering an authentic fieldwork experience.

\section{Significance of the Proposed Project}

A model for a sustainable pro bono clinic will ultimately benefit the students, clients, and the community of each university that uses the model when creating a similar program. It is challenging for schools to provide hands-on learning before Level II fieldwork, which often results in the use of SLE to augment a lack of placements. The goal of SLE is to provide a safe environment for practicing clinical assessment and treatment skills. While the use of SLE has merit, students have reported that if the experience is not well designed, it can lack authenticity (Van Vuuren, 2016). Engaging in the pro bono clinic allows students to participate in experiential learning with genuine clients, helping them to translate knowledge gained in the classroom into confidence in their clinical skills (Phillips, 2017). Similar clinics use the SLE as a tool to assess student readiness before advancing to Level II fieldwork, where they will be expected to perform as entry-level clinicians (Doucet \& Seale, 2012). Providing mentorship to students who struggle with clinical, communication, or administrative skills can have a 
significant impact on their preparedness for clinical practice (Palombaro, Dole, \& Lattanzi, 2011). Pro bono clinics have also been shown to increase the role awareness of other professions (Tsu, Buckley, Early, \& Jackowski, 2018). This increase in interdisciplinary confidence will be beneficial in fieldwork rotations, where students are expected to collaborate and work with a variety of healthcare professionals.

These clinics can help connect clients with rehabilitation services, many of whom are underserved and may not otherwise receive care. Through developing community partnerships universities can generate trust in the community, helping to create referral channels to connect clients with services (Palombaro et al., 2011). In a study conducted by Gertz, Frank, and Blixen (2011), 77\% of patients reported feeling that they had received better care at the free clinic than they had in prior fee-based settings. Clients not only benefit from receiving rehabilitation services, but they also report feeling good about helping students in their learning (Hewson \& Friel, 2004). Participating in pro bono PT services has been shown to reduce pain and increase both physical and mental health (Stickler et al., 2016). Through providing care to those with occupational barriers affecting their ability to live meaningful lives, students demonstrate the professional standards that are expected of an OT.

\section{Preliminary Project Objectives}

1. By four weeks into the project, conduct a needs assessment of St. Johns County and surrounding counties to identify the target population and potential barriers to accessing pro bono clinic services (e.g., transportation).

2. By six weeks, make contact with 2-3 OT programs that have launched student pro bono clinics to learn best practices on developing a sustainable clinic. 
3. By eight weeks, develop a mission statement and vision that is agreed upon by the key stakeholders associated with the clinic.

4. By ten weeks, revise current OT policies and procedures and incorporate them into clinicwide standard operating procedures.

5. By twelve weeks, assess the effectiveness of the pro bono clinic by evaluation of key stakeholders through interviews, focus groups, and observations.

6. By the end of the project, draft and disseminate a strategic plan that offers a SWOT analysis based on learnings from the capstone experience.

\section{Definition of Terms}

Business Plan. "A document setting out a business's future objectives and strategies for achieving them" (“Business Plan”, 2019, para. 1).

Experiential Learning. The use of direct experiences as an adjunct to a traditional academic setting to promote knowledge and skill development ("What is Experiential Learning", 2019). Define, Measure, Analyze, Improve, and Control (DMAIC). The problem-solving approach used in Six Sigma that drives process improvement (“Learn about Quality”, 2020)

Grand Rounds. An approach to teaching whereby students and instructors gather and discuss the diagnosis and treatment of clients (Sandal, Iannuzzi, \& Knohl, 2013).

Occupational Justice. An extension of social justice that recognizes the right of every individual to enjoy the right and ability to fully participate in meaningful occupations (Townsend \& Wilcock, 2004).

PRECEDE-PROCEED model. A comprehensive model outlining a process for health education and promotion programs that started with the development of PRECEDE by Lawrence Green in 1974, with PROCEED added in 1991 by Green and Kreuter (as cited in Porter, 2016). 
Simulated Learning Experience. A method of teaching clinical skills using simulated clients to imitate real-life scenarios through various modalities such as case studies, student role-plays, and actors trained to play the part of a client (Van Vuuren, 2016).

Six Sigma. A framework traditionally used in business to achieve optimal value for shareholders through improvements in speed, quality, customer service, and costs (Laureani \& Antony, 2018) Stakeholder. Any party with relation to an organization that can directly affect or be affected by the business ("Stakeholder", 2019). In terms of a pro bono clinic, this would include the clients, students, and faculty members.

SWOT Analysis. A leadership tool to assess strengths, weaknesses, opportunities, and threats. SWOT analyses are conducted across business industries for strategic planning (Blayney, 2008). A SWOT analysis provides a framework for evaluating both internal and external components of a business to build upon strengths, drive development through opportunities, and mitigate threats to sustainability and success.

\section{Assumptions}

This capstone project assumed that the pro bono clinic would be continuously sponsored by the USAHS and operated by faculty with student participation. It was assumed that the small sample size of focus groups, interviews, and observations would be generalizable to the key stakeholders as a whole. It was also assumed that the information provided by other universities related to best practices for implementing a pro bono clinic would apply to our region, demographic, and program.

\section{Conclusion}

Student pro bono clinics can provide a unique learning opportunity while improving access to care for the underserved in the community (George et al., 2017). While these programs 
can benefit multiple stakeholders, they often face barriers to sustainability due to challenges experienced by the underserved population (Delahunt et al., 2018). Further, there is limited literature on planning and implementing OT-specific clinics. Therefore, a search of available research on the use of pro bono clinics by other healthcare disciplines was conducted to inform the development of a sustainable strategic model for the OT profession. 


\section{Chapter 2: Literature Review}

\section{Introduction}

The need to advocate and bring services to the underserved population continues to grow. According to Collins, Bhupal, and Doty (2019), 45\% of Americans today are inadequately insured, placing them at a higher risk of facing barriers to occupational engagement and access to OT (Braveman \& Suarez-Balcazar, 2009). Through a student pro bono clinic, the underserved receive care while students improve upon skills, and the university gives back to the community. The purpose of this chapter is to review the available literature related to the benefits of a pro bono clinic for students, the community, and the university, as well as on the development and sustainability of a student clinic.

\section{Benefits of Hands-on Practice for Health Care Students}

The clinical experience gained by students engaging in hands-on patient care is a topic that has been investigated throughout the health care professions. Research has found that the use of pro bono services is an effective way of improving student readiness for clinical practice (Black et al., 2017; Cassidy \& Yorke, 2019; Dhans et al., 2015; Palombaro et al., 2011). In a study conducted by Hewson and Friel (2004), 80\% of second-year PT students reported increased confidence in their clinical skills after participating in a pro bono clinic. The benefits of student participation in these community programs have led to their implementation in many disciplines. Student clinics have become so prevalent that in 2010, the Society of Student-Run Free Clinics was formed, which now consists of 152 multidisciplinary clinics in 31 states. This organization serves as a national interprofessional platform for faculty and student leaders to collaborate on experiences related to student clinics ("Creation of SSFRC”, n.d.). 
While literature explicitly related to OT pro bono clinics is limited, evidence from the PT profession is promising. A pro bono clinic at Widener University Institute for Physical Therapy Education included students from all three years in the DPT program (Black et al., 2017). Students were broken into teams consisting of a first, second, and third-year student. The founders used a Grand Rounds format to encourage interaction between students in various stages of the program and to improve the transfer of pre-clinical learning to clinical skills (Black et al., 2017). Use of the Grand Rounds, in conjunction with a pro bono clinic, proved beneficial for students from each year of the program. Significant improvements were made in clinical skill areas such as client progression, alteration of a plan of care, and familiarity with clients and programs (Black et al., 2017). Third-year students reported that they felt participating in the clinic earlier in the PT program would have improved their confidence and development of clinical skills.

\section{Student Impact of Pro Bono Clinics}

Participation in a pro bono clinic offers not only hands-on practice, but also experience in areas such as interprofessional communication, leadership, and administration (Ries, 2010; Tsu et al., 2018). Campbell et al. (2015) surveyed fieldwork educators' expectations of students on Level II fieldwork. One hundred percent of respondents reported that clinical competence, communication skills, and time efficiency are "essential” skills (Campbell et al., 2015, p. 6). Time spent in the pro bono clinic allows students to work on all of these skills in a controlled environment, having instructors present to provide feedback and assistance as needed. This experience is a good segue into client care and has been found to reduce feelings of anxiety about going on Level II rotations (Hewson \& Friel, 2004). 
Students from five health care disciplines reported that the pro bono experience resulted in increased awareness of the importance of interprofessional collaboration in providing holistic, client-centered care (Hu, Cox, \& Nyhof-Young, 2018). The clinic allows students to work with and learn from other professions, getting an authentic experience of the overlap of health care disciplines, especially in complex clients with comorbidities. As a part of improving communication skills, working in a multidisciplinary clinic allows OT students to educate both their clients and other professions on the role of OT in the care continuum (Rogers, Heck, Kohnert, Paode, \& Harrell, 2017). This experience not only helps to create awareness of the OT scope of practice among other professions but also helps students to clearly articulate the purpose and importance of OT. Rogers et al. (2017) also found that the multidisciplinary clinic experience had a positive impact on students' ability to build rapport, engage their therapeutic use of self, and comfortably interact with clients and other professionals.

According to Rogers et al. (2017), including OT students in an interprofessional student clinic prepares them to become emerging leaders within the profession. Much of the literature on pro bono clinics incorporates an element of student leadership, frequently through the use of a student leadership board. George et al. (2017) implemented an executive board for the clinic at Indiana University, where elected students assumed responsibility for all aspects of clinic operations. To increase the impact of the experience, faculty advisors provided oversight to the board, offering assistance with decision making and communication. The program provided leadership not only through board positions but also by including first-year PT students in the clinic, where they received mentorship from upper-level students (George et al., 2017). These community programs offer various opportunities for students to build valuable leadership skills, which is an essential asset as they progress in their careers. 
In the dynamic world of health care where time management and efficiency are paramount, proficiency in administration and documentation are critical for entry-level practitioners. In a study conducted by Black, Palombaro, and Dole (2013), participation in a pro bono clinic resulted in improved PT student confidence in administrative skills. The experience allows students to use real client interactions to complete administrative tasks. The mentorship of faculty members creates an opportunity to have documentation reviewed, providing constructive feedback that can help to improve documentation skills before Level II fieldwork rotations. To realize these benefits, student pro bono clinics must be designed to optimally facilitate the student-faculty relationship. Future programs can take advantage of the best practices identified and outlined in the capstone program's strategic plan for operating a pro bono clinic.

\section{University Impact of Pro Bono Clinics}

A university-sponsored pro bono clinic is a great engagement initiative that lends benefits to the student therapists and the surrounding community. The experiential learning provided by student clinics helps students translate classroom knowledge into clinical skills (Dhans et al., 2015; Phillips, 2017). A university gains many benefits from sponsoring a pro bono clinic. It enhances student preparedness for practice and provides an authentic Level I fieldwork experience. Further, it demonstrates the value of altruism and the principle of justice (AOTA, 2015) by offering therapy to the underserved in the community.

Academic performance is not always representative of a students' readiness for clinical practice, which lends merit to the use of practice education approaches (Hamilton et al., 2015). Sponsoring a pro bono clinic does not just fulfill a portion of Level I fieldwork requirements. Participating in the clinic offers excellent utility in increasing students' self-confidence in their clinical skills. When moving on to Level II rotations, students' self-efficacy in their clinical skills 
is key to successful performance (Andonian, 2017). In a study conducted by Doucet and Seale (2012), 93\% of OT student therapists taking part in a free stroke clinic reported feeling more prepared for clinical rotations after participating.

The faculty oversight during the pro bono experience can allow for the identification of students that have low self-efficacy or deficits in the skills necessary to be successful on fieldwork rotations (Froberg et al., 2018). Early identification gives the faculty time to mentor and help students enhance these skills, resulting in better preparation for clinical practice. Students report the relationships with faculty provide guidance and continuous feedback that result in satisfactory and meaningful experiences (Froberg et al., 2018).

Not only does the university provision of a pro bono clinic help to generate betterprepared students, it also demonstrates a commitment to improving the public health of the local community. The OT literature emphasizes the concept of occupational justice, which refers to a societal obligation to ensure that people have access to occupational opportunities (Braveman \& Bass-Haugen, 2009). Those with disabilities are at increased likelihood of facing barriers that restrict their participation in the community and employment, further limiting their access to resources such as OT (Braveman \& Suarez-Balcazar, 2009). In offering this community-based program, the university portrays an altruistic image. The program itself, builds relationships and provides services to the underserved population, ultimately increasing occupational justice in the community.

\section{Unique Opportunity for Fieldwork Experience}

With the rapid growth of the OT profession, it is becoming increasingly challenging both nationally and internationally to secure enough fieldwork placements to meet the required hours for the profession (Anita et al., 2015; Evenson, Roberts, Kaldenberg, Barnes, \& Ozelie, 2015). A 
need for innovative solutions has led to a growth in the use of simulated learning experiences (SLE) to augment a deficit in fieldwork sites. The goal of an SLE is to create as realistic of an experience as possible through the use of various interventions such as standardized clients, written case scenarios, role-plays with other students, and video simulations (Bennett, Rodger, Fitzgerald, \& Gibson, 2017). While SLEs can create an experiential learning environment, several considerations must be kept in mind to ensure their utility.

Although SLEs have been shown to improve competencies using a low-risk environment, they must be designed and executed appropriately to ensure a genuine experience (Bennett et al., 2017). The level of authenticity depends upon the simulated client accurately portraying the targeted condition, which typically presents according to textbook information. Researchers have noted that while the use of SLEs can be beneficial, they are not the same as watching students provide care to real clients (Van Vuuren, 2016). Creating a high-fidelity learning environment can also be a financial burden on the university, with high costs to provide standardized clients and to build and staff simulation labs (Bennett et al., 2017). While sponsoring a pro bono clinic has associated financial costs, it affords student exposure to real clients, challenging their ability to adapt to the unique situation of each client.

\section{Client Impact of Pro Bono Clinics}

A pro bono clinic provides access to services to the underserved in the community, many of whom are uninsured or underinsured and would not otherwise receive therapy. Conditions such as musculoskeletal impairments, which are the primary cause of debility in the U.S., result in a loss of ability to perform occupations, creating a financial burden for the client, their family, and the workforce due to lost wages and productivity (Carvalho, Bettger, \& Goode, 2017). These conditions are particularly problematic in the target population of a pro bono clinic, as they are 
more prevalent in those without health insurance, as well as those with a low income or education level (Choi, Park, \& Cheong, 2013).

A study conducted by Kian et al. (2018) found that clients of the pro bono clinic reported very high satisfaction in both the client experience and the quality of care received. Hu et al. (2018) noted that clients that attended student clinics reported comparable outcomes to those achieved by traditional health care services. In Doucet and Seale's (2012) study, 93\% of client participants in the free student stroke clinic offering PT and OT services reported functional progress after attending the clinic. This improvement ultimately helped to increase participation in meaningful occupations. While few studies have been completed documenting overall client satisfaction with student clinics specializing in general rehabilitative services, the consistency of service provision by OT student therapists has been shown to result in higher levels of client satisfaction (Black et al., 2017). As OT professionals are skilled in building rapport through the therapeutic use of self, it is understandable that the experience would feel more client-centered with the consistent care of student therapists.

Not only do student pro bono clinics assist clients with returning to meaningful occupations, but participants report they feel important because they are helping student therapists improve upon their clinical and communication skills (Hewson \& Friel, 2004). Stickler et al. (2016) found that clients had a notable increase in mental health after attending a PT student clinic. The positive impacts on mental health create intrinsic motivation for continued attendance, which enhances the relationship between client and student-therapist and enriches the learning experience. 


\section{Developing a Pro Bono Clinic}

Student pro bono clinics have been developed by a range of health care disciplines using many different models, but there are limited OT-specific resources. During the development of a multidisciplinary student-led clinic at Indiana University, a literature review conducted by Rogers et al. (2017) found limited guidance on navigating the start-up process and what role the faculty should play in facilitating learning opportunities. Additionally, George et al. (2017) described the sparsity of available resources to guide the implementation and faculty in using the said clinic to provide learning opportunities for students.

Gaffney (2019) proposed a series of steps for the development of a pediatric clinic based on her efforts at Gannon University. The first phase, she explained, is conducting a needs assessment to determine the target population. This step is critical to understanding the community landscape and targeting people who would most benefit from pro bono services. Palombaro et al. (2011) suggested the initial emphasis should be on aligning the mission and vision of the program with those of the university. These founding efforts can be used to determine the clinic objectives and develop a strategic plan.

After conducting a needs assessment and establishing a mission statement, the phases of clinic development vary by model and discipline. Common themes include steps such as securing space and financing, finding faculty support, forming a student board, and creating policies and procedures to help guide the clinic towards the vision (Gaffney, 2019; George et al., 2017; Palombaro et al., 2011; Rogers et al. 2017). Beginning clinic operations with a welldesigned plan can help to ensure an enduring community-based program that remains focused on efficiently and effectively assisting the underserved. 
Many programs experience challenges during the development and implementation phases, making it essential to start small (Smith, Cohen, \& Raybuck, 2006). A modest approach to starting a service-learning program allows for time to identify best practices for executing operations. Beginning the clinic offering on a small scale and building on strengths can reduce the burden of having to make changes as opportunities are identified. While this may extend the development and implementation processes, it is a strategic move that helps provide the foundation for a successful clinic (Smith et al., 2006).

\section{Sustaining a Pro Bono Clinic}

Continued operations of a pro bono clinic are dependent upon the execution of a comprehensive strategic plan that considers strengths, weaknesses, opportunities, and threats to sustainability (Cassidy \& Yorke, 2019; Delahunt et al., 2018; Phillips, 2018). Careful planning during clinic development helps to anticipate challenges and to proactively put strategies in place to reduce the impact of the barriers. Further, looking at the obstacles similar programs have faced may help to inform risk mitigation strategies.

Zachry, Allen, Dickey, and Moore (2016) reported establishing community partnerships and having a unified vision are essential to maintaining operations. As a community-based program, it is vital to reach out to area organizations that serve the target population. Building genuine relationships with community organizations can bring credibility to the clinic and provide a good source of client referrals (Palombaro et al., 2011). Marketing efforts must be planned and targeted; similar clinics have identified a lack of consistent marketing as a barrier to survival (Delahunt et al., 2018).

The literature suggests transportation is another common barrier for pro bono clinics. Delahunt et al. (2018) also reported high rates of cancellations and no-shows were due to a lack 
of reliable transportation and the inability of clients to take time off work. Kamimura et al. (2018) found that $20 \%$ of free clinic patients missed appointments due to transportation barriers and that this barrier negatively impacted general health. Inconsistent attendance of therapy appointments adversely impacts client outcomes, which may negatively affect client satisfaction with the student clinic.

Another crucial component of sustainability is student involvement. Smith et al. (2006) noted that a quality service-learning program engages students, connects the service experience with academic coursework, and includes students in all aspects of the decision-making process. Students can help to identify the needs of the community, market the program to local agencies, and conduct research related to the effectiveness of the program. Increased student engagement improves buy-in, enhances skill development, and helps to create a sense of pride in executing a successful clinic (Black et al., 2013).

George et al. (2017) created a strategy for sustainability based on earlier work by Palombaro et al. (2011), which has proven effective in practice. The strategy put forth by George et al. (2017) at Indiana University consists of six key aspects to ensure operational continuance of a multidisciplinary clinic: "(1) effective clinic partners, (2) low operating cost, (3) risk management policies, (4) dedicated student leadership, (5) efficient operations, and (6) reduction of health care barriers" (p. 60). By proactively planning for these challenges, the student outreach clinic at Indiana University continues to serve the Indianapolis community.

\section{Theory}

The theoretical approach for this capstone was based on the PRECEDE-PROCEED model (PPM), which was developed by Lawrence Green and Marshall Kreuter as an ethical guide for health promotion practice (Porter, 2016). This model has been used by public health 
professionals in the development of many programs across disciplines aimed at improving community health, such as for reducing blood pressure in community-dwelling adults with hypertension (Calano et al., 2019) and improving the quality of life in diabetic patients (Azar, Solhi, Amani, \& Nejhaddadgar, 2017). The PPM has been successfully used in combination with service-learning to teach PT students health and wellness and to guide them through developing community health promotion projects (Tapley \& Patel, 2016). According to Morris and Jenkins (2018), the PPM is an essential model in OT and PT curriculum for developing entry-level health promotion practitioners.

The PRECEDE portion of the model, which stands for predisposing, reinforcing, and enabling constructs in educational diagnosis and evaluation, is the process used for the development of an intervention (Tapley \& Patel, 2016). This portion of the model consists of four phases. It begins with identifying the quality of life concerns of the target population and developing program elements based on the defined goals (Morris \& Jenkins, 2018). The PRECEDE phases support conducting a needs assessment, establishing objectives for the pro bono clinic based on those needs, and developing policies and procedures that align the program with the university. These phases represent the planning and organizational stages of model development for a pro bono clinic.

Phases 5-8 of the model focus on implementation and evaluation of the program and are known as the PROCEED portion, which is an acronym for policy, regulatory, and organizational constructs in educational and environmental development (Tapley \& Patel, 2016). During PROCEED, there is a focus on not only program implementation, but also on continuous quality improvement (Green \& Kreuter, 1999). While the ultimate goals of PROCEED are to evaluate the program and to realize the short and long-term objectives, the inherent concern of a 
community-based pro bono clinic is longevity. To this end, opportunities discovered through implementation and evaluation of the student clinic can be incorporated into practice to improve upon strengths and to increase the ability to operate sustainably.

\section{Conclusion}

The provision of a student clinic has been shown to benefit the students in multiple facets of skill development while providing the underserved in the community access to services they may not otherwise attain (George et al., 2017). Therefore, student pro bono clinics developed by many universities, encompassing a variety of health care disciplines. Keeping the benefits to student, community, and university is essential in all phases of clinic development.

Consequentially, a theory-based model is necessary to strategically implement and sustain a pro bono clinic. Gaffney (2019) proposed essential steps to be taken when developing a pediatric OT pro bono clinic. While these are useful guidelines, a comprehensive model for operating a community-based program specific to the profession will be beneficial to OT programs nationwide. 


\section{Chapter 3: Project Description}

\section{Introduction}

The purpose of this capstone project was to create a model for operating a student pro bono clinic that will serve as a reference for OT programs starting clinics in the future. This model will help future applications to operate in a sustainable manner that optimizes the benefits for clients and student therapists. This capstone was grounded in the PPM, which is a proven process for developing and evaluating health promotion programs (Porter, 2016). The project began with a needs assessment, evaluating the demand from both a community and a student perspective. A search was conducted for other universities that have started OT student pro bono clinics. Representatives from three programs were contacted to determine best practices for operating and sustaining a clinic. Feedback on current policies and procedures was gathered from key stakeholders through observations, focus groups, and interviews. This information became the foundation for a strategic model, which was developed to inform future University of St. Augustine for Health Sciences (USAHS) clinic operations and to guide other universities starting similar programs.

\section{Participants}

This project was conducted mainly through a review of documents on policies and procedures, as well as through observation of students, faculty, and clients. Interviews and focus groups were conducted to assess the effectiveness of the pro bono clinic operations. The participants consisted of volunteer second term and fourth term OT students, faculty with a vested interest in the clinic, and clients utilizing the services. 


\section{Setting}

This capstone project was conducted at the campus of USAHS. All key stakeholders, including students, faculty, and clients, were present during the time frame of the project. The pro bono clinic operates on the USAHS campus, utilizing an open lab space with treatment tables sectioned off for therapy sessions. The clinic initially only offered PT services, but began providing OT in January 2019. Services are provided by student therapists while being overseen by faculty members who are licensed OTs. The majority of clients seeking treatment at the USAHS pro bono clinic present with musculoskeletal injuries, chronic medical conditions, and general debility secondary to aging. The clinic offers nine weeks of OT services each term, with fourth term students participating in a minimum of a two-week rotation as a part of Level I fieldwork. Students and faculty participate in both academic courses and the pro bono clinic within the building, making it an ideal setting for conducting observations, interviews, and focus groups.

\section{Development}

The program development was based on the first four phases of the PPM. These phases are focused on identifying the needs of the community and on developing objectives based on identified needs and input from key stakeholders (Morris \& Jenkins, 2018). According to Green and Kreuter (1999), a hallmark of this model is flexibility, which is important due to the uniqueness of this capstone project. Since the pro bono clinic was already operational, the program development phase consisted of retroactively conducting the planning phases of building a not-for-profit community clinic. This process was essential to ensure a foundation based upon a robust assessment of the population and clinic objectives that align with those needs. Even though the program already inherently had a target population, it was essential to 
confirm that the clinic goals were related to the quality of life concerns of the community (Gielen, McDonald, Gary, \& Bone, 2008). Ensuring the appropriateness of goals was accomplished by conducting a needs assessment.

Phase two and three of PPM include an epidemiological and educational assessment (Green \& Kreuter, 1999). These were addressed through an assessment of St. Johns county, evaluating the breadth and needs of the local underserved population, as well as the behavioral and environmental barriers that can hinder attendance. Methods used to complete these phases included a literature review, as well as an internet search of government reports, public data, and news articles. As recommended by Gielen et al. (2008), consulting the body of literature is a valuable way to shorten some of the earlier phases when addressing commonly identified community health issues. It was, however, essential to develop clinic objectives based on community needs. Therefore, contact was made with local organizations, including the Council on Aging, Wildflower Clinic, Flagler Hospital, and the Veteran Affairs clinic.

It was equally important to consider the needs of the student therapists and include them in the planning phases (Palombaro et al., 2011). These community programs have the potential to improve clinical, administrative, communication, and leadership skills (Black et al., 2017; Ries, 2010; Tsu et al., 2018). Informal focus groups were conducted with second term OT students volunteering for administrative and rehabilitation tech roles, as well as with fourth term OT students before participation in the pro bono clinic. Information gathered from these groups was used to help optimize the student experience. The recommended size of a focus group is four to 12 participants (Tang \& Davis, 1995). While one group, conducted with the previous term of pro bono students, had 38 participants, the average attendance for structured focus groups during this capstone was eight students. Groups were conducted by this researcher with no faculty members 
present, using the format for conducting focus groups outlined by Doody, Slevin, and Taggart (2013), and Harrell and Bradley (2009). While questions were structured, probing questions were used to ensure each student had the opportunity to contribute their opinions. The groups were not recorded using video or audio. The information collected by this researcher included verbal dynamics of the group and a summary of emergent themes. Students were recruited voluntarily following a clinic briefing before the beginning of each two-week rotation. The objective of these groups was to gain insight into the student needs and expectations before starting in the pro bono clinic. While the faculty determines the student objectives for participation in the clinic, those objectives must address unmet student needs. Therefore, the takeaways from these meetings were compared with current clinic objectives and policies to identify opportunities for improvement.

The last phase of the PRECEDE portion of PPM is used to align the program components with the assessments conducted in the first three phases (Green \& Kreuter, 1999). The information obtained from the needs assessments was used to develop a mission and vision statement for the clinic, as well as a policy and procedure manual. Throughout the PRECEDE phases, research was also conducted to determine OT programs with operational pro bono clinics in the Southeastern United States. Interviews were conducted with key stakeholders from three such universities to gain insight into their experiences developing and operating a student clinic. Gaining an understanding of the process and the lessons learned by other schools informed USAHS efforts to create a sustainable clinic. The sharing of best practices by other programs was instrumental in the development of a comprehensive policy and procedures manual. 


\section{Implementation}

The first phase of PROCEED is the implementation of the program. The pro bono clinic at USAHS already provides PT services and has been offering OT for two terms. The clinic schedule continued as planned during this project. Despite the general interdisciplinary focus, there were different objectives and operating procedures for the two disciplines participating in the clinic. Faculty from PT and OT were involved throughout the process so that the standard operating procedures (SOP) accurately portrayed both disciplines. According to Palombaro et al. (2011), one of the most important steps to operating a sustainable clinic is ensuring the mission of the program aligns with that of the university. Therefore, the first step in developing the SOP was to propose a unified mission statement and vision that were inclusive of all parties and parallel with those of USAHS. Meetings with involved faculty were held as the SOP evolved to discuss objectives, policies, and procedures, and how to best capture their needs in the document.

The six-week operational period of the clinic was used for observation and evaluation of the objectives and policies and procedures of both disciplines. Data from these observations and information gathered during the PRECEDE phases were used to compile one SOP for use throughout the clinic. The SOP was updated throughout the clinic's duration as opportunities were identified. This strategy was in keeping with PPM, which emphasizes continuous quality improvement (Green \& Kreuter, 1999). Clinic operations were assessed using a Six Sigma approach. This framework is traditionally used in business to achieve optimal value for shareholders through improvements in speed, quality, customer service, and costs (Laureani \& Antony, 2018). This approach can be applied in health care to improve the quality of care while reducing process inefficiencies (O’Brien, 2019). The problem-solving approach offered by the 
Six Sigma methodology is the Define, Measure, Analyze, Improve, and Control (DMAIC) process ("Learn about quality", 2020). Procedures, including referrals, scheduling, client flow, and documentation, were evaluated through observations, interviews, and focus groups to identify opportunities for improvement, which were then addressed using DMAIC.

\section{Evaluation}

The final three phases of PROCEED consist of an evaluation of the process, impact, and outcomes of the program (Morris \& Jenkins, 2018). The process and impact evaluations focus on the implementation and short-term effects of the program, which were valuable in finalizing the SOP and in developing a SWOT and strategic plan for sustainability. Phase eight is an outcome evaluation, which examines the long-term effects, such as improvement in client quality of life (Green \& Kreuter, 1999). This evaluation was outside the scope of this project but would be a good avenue for future research.

Feedback from key stakeholders was gathered throughout clinic operations to assess and improve processes. Focus groups are commonly used in healthcare settings to gain an understanding of the opinions and perceptions of individuals related to a specific topic (Then, Rankin, \& Ali, 2014). Focus groups were conducted with fourth term OT students at the end of each two-week rotation to determine the effectiveness of the clinic in meeting their objectives and expectations. Volunteers for these groups were recruited from the clinic debriefs that occurred at the completion of each rotation. These groups were conducted with an average size of eight volunteers. Voluntary client feedback on the clinic processes was also collected, typically after they had finished their therapy sessions. Finally, there were meetings with the faculty members involved in the clinic processes. Through contact with each of these 
populations, total quality improvement of the client flow and of the student and faculty experience were performed.

The information gathered during the clinic operations through observation and feedback was used to finalize a SWOT analysis, SOP for clinic operations, and a strategic plan for sustainability and provision of an optimal experience. A strategic plan is a necessary step in documenting the current state of a program, as well as for outlining its goals and future direction (Johnson, 1990). This document was created to serve as a guideline for conducting pro bono clinic operations in a sustainable manner utilizing the best practices learned throughout the development and implementation processes.

\section{Alignment with Objectives}

The objectives of this capstone were accomplished through the development, implementation, and evaluation of the pro bono clinic. During the development phases, a needs assessment was conducted to ensure the clinic met the needs of the community and the expectations of students. Other universities with operational pro bono clinics were contacted to solicit best practices to inform the structure, policies, and procedures of the USAHS clinic. Meeting these objectives allowed for a smooth transition into the implementation phase.

The creation of a mission and vision began the implementation phase, laying the foundation for drafting an SOP. Meetings with university faculty were held to ensure that the clinic mission aligned with that of USAHS and was interdisciplinary in content. The policies and procedures from OT and PT that had been used in previous terms of clinic operations were compared and merged into a clinic-wide SOP. This manual of policies and procedures was evaluated and modified as opportunities were identified during the six-week program. 
The evaluation phases were built into the project to maximize stakeholder input, occurring throughout the pro bono clinic operations. Feedback from key stakeholders on quality improvement opportunities was critical for completing a SWOT analysis and for developing a strategic plan. Voluntary focus groups were conducted to incorporate the opinions of students by learning the strengths and weaknesses of the students' experiences. Informal interviews were also held with clients to gain an understanding of the client flow process. Feedback was obtained from faculty involved in the clinic to ensure their opinions for improving clinic operations were included in the strategic planning process.

A SWOT analysis was performed using the observations of clinic operations and feedback received from stakeholders. This analysis was utilized to finish the strategic plan, which was distributed to the leadership team of the pro bono clinic. The strategic plan will serve as a guideline for operating a sustainable clinic that continues to move toward the clinic's vision. Dissemination of the strategic plan marked the completion of all capstone objectives.

\section{Conceptual Framework}

A logic model is useful in improving program direction and strategy through the identification of the program inputs, activities, and outcomes (Milstein \& Wetterhall, 1999). This model demands an appreciation for the relationship between activities and outcomes in public health programs and helps to identify areas for future research (Baxter, Killoran, Kelly, \& Goyder, 2010). The logic model separates the outcomes into short-term, immediate, and distal, which can be beneficial in strategic planning to ensure the success of long-term goals.

The inputs include the resources that go into a program (Milstein \& Wetterhall, 1999). The USAHS provided all equipment and supplies needed for pro bono clinic operations, as well as a facility for therapy to take place. Students were readily available to provide therapy, as each 
OT student had a scheduled two-week rotation in the clinic. There were licensed OT and PT faculty members on-site to supervise treatments and to mentor students. While client documentation for OT had historically been completed on paper, an electronic medical record (EMR) system was implemented during this project. Client referrals were generated mostly by word of mouth in previous terms. Therefore an effort was made to raise community awareness in order to create a steady referral source.

The activities include all of the events that took place during the capstone experience. A needs assessment was conducted to ensure the alignment of the program objectives with student expectations and the needs of the community. Interviews were held with leaders of other universities that offer OT pro bono services to compare best practices for clinic operation and sustainability. This information was utilized to create an initial draft of a policy and procedure manual before the start of the USAHS pro bono clinic.

The pro bono clinic was the main activity that took place during this capstone project. The six weeks of clinic operations were used as a period of observation to identify opportunities for increased efficiency and optimization of the experience. All services were provided by student therapists supervised by licensed OT and PT faculty. During this time, the clinic mission, objectives, and SOP were revised and finalized. Interviews and focus groups with stakeholders helped to identify quality improvement opportunities and assisted in the completion of a strategic plan for a sustainable program.

The SOP and strategic plan were the final products of this capstone, which differed from outcomes in that they were tangible outputs (Milstein \& Wetterhall, 1999). There were several short-term outcomes expected as a result of improving the pro bono experience. Student therapists would benefit from increased efficiency, allowing them to spend more time providing 
therapy and improving their clinical skills. Faculty members would be afforded more time to provide mentorship to students, enhancing the experience for both student and client. The intermediate benefits included having centralized operating procedures and providing leadership with a clear mission and vision for the future of the program. Finally, greater awareness of the program among local organizations increased the potential of creating strong community partnerships.

Distal outcomes were the long-term goals of the pro bono clinic, which fell outside of the scope of this project. The strategic plan will serve as a roadmap for the achievement of distal outcomes. The focus of this capstone project was to improve the program experience for stakeholders, which included clients, students, the university, and the community. The long-term benefits that will be realized by these stakeholders would be an area for future research.

\section{Timeline}

The first six weeks of the project were dedicated to conducting a needs assessment of the local community and student population to ensure the clinic objectives aligned with the needs of stakeholders. Contact was also made with three other universities offering OT student clinics to gain an understanding of lessons learned during the implementation and operation of similar programs. Finally, available policies and procedures that had been used in previous terms of the USAHS pro bono clinic were gathered and compared with identified stakeholder needs.

The following four weeks included the development of the clinic mission and vision, as well as an initial draft of the SOP, which was updated as observations were made during pro bono operations. The collection of feedback from stakeholders was largely completed by Week 10 but continued throughout the remainder of the six-week clinic. As a part of continuous quality improvement efforts, the opinions of stakeholders were used to identify policies and procedures 
with opportunities for improvement. Stakeholder feedback was instrumental in the completion of the SWOT analysis and strategic plan, which were disseminated to the lead faculty at the end of the capstone experience.

\section{Conclusion}

The project objectives for this capstone were accomplished by aligning the development of the strategic model with the PPM. Using a proven model in health program planning helped to organize and complete the objectives in a logical sequence. Through first considering the community and students, the USAHS pro bono clinic was built around fulfilling unmet needs. Collecting feedback from stakeholders throughout the implementation process helped to identify gaps in policies and procedures, ultimately improving clinic efficiencies and the pro bono experience for all. The information discovered through the literature review, program planning, and implementation processes was essential to finalizing a SWOT analysis and the strategic plan. The completion of each capstone objective provided valuable information that will be useful to other OT programs when developing and launching a student pro bono clinic. 


\section{Chapter 4: Results}

\section{Introduction}

The purpose of this capstone project was to develop a model for creating a sustainable OT student pro bono clinic. The execution of this project was based on the steps outlined by the PPM, a process that has been successfully used for health promotion programs (Porter, 2016). The project began with a needs assessment, which is the recommended first step in developing an OT pro bono clinic (Gaffney, 2019). This assessment, along with feedback from key stakeholders and investigation of best practices from universities with similar programs, laid the foundation for the development of the clinic objectives, mission, and vision statements. Through participation in clinic operations and collaboration with stakeholders, gaps in policies were identified and incorporated into a clinic SOP manual. Opportunities for process improvement were acknowledged during the course of the six-week program, which led to continuous refinement of clinic procedures and the policy manual. Using observations from the clinic operations and feedback from students, faculty, and clients, a final SWOT analysis and strategic plan was created to increase the clinic's ability to sustain operations in future terms.

\section{Community Needs Assessment}

As explained by Gaffney (2019), the first step in planning a community-based program is to conduct a needs assessment. Understanding the community landscape and areas of opportunity can help to inform the goals and objectives of the program. While the pro bono clinic at USAHS was operational prior to the start of this capstone project, a retrospective assessment was performed to confirm that the clinic mission had a solid foundation and that its policies and procedures aligned with the community needs. 
The initial plan was to evaluate St. Johns County, Florida and surrounding areas that would benefit from the USAHS pro bono clinic. After researching business planning and reading The Centers for Disease Control and Prevention (CDC) (2013) guidelines for conducting a community needs assessment, the focus was narrowed to the local St. Augustine area. The CDC (2013) reports that a more significant impact can often be attained by starting with a smaller sized community. The demographics for surrounding counties are included for informational purposes, and to give context for how St. Johns County compares to its neighboring counties.

The needs assessment was conducted from November 2019 to December 2019, and aimed to assess the following:

- The demographics of the St. Johns County community

- The objectives of the St. Johns County government entities, as related to public health

- Community organizations designed to aid the underserved

- Including their mission and vision statements to help inform the mission and vision of the USAHS pro bono clinic

- Stakeholders from organizations that may serve as referral networks

- Barriers to the accessibility of the USAHS pro bono clinic

- Public transportation available in the area

The needs assessment was performed through reviewing electronic data sources and by conducting individual interviews with stakeholders from local organizations. The initial phase was a comprehensive search of government and community organizations with a focus on assisting the underserved population. Several vital organizations were discovered through the search, including The Council on Aging, Veterans Affairs, St. John's County Care Connect, the Wildflower Clinic, and Northeast Florida Area Health Education Centers. When doing 
background research on other community organizations and programs, the initial priority was to assess their mission and vision statements. Before making contact, it was essential to ensure that their objectives were charitable and focused on improving community health. Searches for published documents, news and public relations information, and resources provided by each organization were critical in the completion of this assessment. Identifying appropriate organizations helped to locate leaders with a keen awareness of community health problems.

After the initial search, the next objective was to identify the area demographics to assess the breadth of the underserved population. A search of public census data provided a high-level overview of the population statistics. While the target community for the pro bono clinic was St. Johns County, surrounding counties were included for comparison.

Table 1

Demographics of St. Johns and Surrounding Counties

\begin{tabular}{|l|c|c|c|c|}
\hline & St. Johns & Putnam & Duval & Flagler \\
\hline Uninsured Rate (Under 65) & $10.6 \%$ & $17.2 \%$ & $13.2 \%$ & $14.7 \%$ \\
\hline Persons with Disability & $7.6 \%$ & $13.2 \%$ & $9.8 \%$ & $10.7 \%$ \\
\hline Under 65) & & & & \\
\hline Poverty Rate & $8.3 \%$ & $26.3 \%$ & $15.1 \%$ & $12 \%$ \\
\hline Population Over 65 & $20.2 \%$ & $23.2 \%$ & $14 \%$ & $30.7 \%$ \\
\hline Unemployment Rate & $2.4 \%$ & $4.6 \%$ & $3.7 \%$ & $4 \%$ \\
\hline Population & 254,261 & 74,163 & 950,181 & 112,067 \\
\hline
\end{tabular}

Note. Data for St. Johns and surrounding county demographics from the United States Census Bureau, 2017. 
It was evident through reviewing the data that St. Johns County has a lower uninsured and poverty rate than neighboring counties. According to the Institute for Health Metrics and Evaluation (2016), residents of St. Johns County have a longer life expectancy and lower mortality rate from chronic health conditions than the national average. While the data appears positive in relation to nearby communities, there is still a significant number of people who may benefit from pro bono services. Nearly $30 \%$ of the population is either uninsured, disabled, impoverished, or unemployed.

To gain a better understanding of health issues in the community, a search of documents from the Florida Department of Health (DOH) in St. Johns County was performed. Since 2005, a council appointed by the DOH has performed in-depth community health assessments of St. Johns County every three years (St. Johns County Health Leadership Council, 2019). The results are used to inform community improvement plans. Surveys and focus groups are conducted throughout the community, offering useful insights into the opinions and thoughts of residents from all backgrounds. The latest assessment was performed in 2017, with the current public health initiatives spanning 2018-2020. Surveys conducted in 2017 revealed that the most significant barriers to getting health care were: "1) Inability to pay, 2) lack of convenient business hours, 3) long wait times for appointments, and 4) inability to find providers innetwork” (St. Johns County Health Leadership Council, 2019, p. 26).

One of the most common barriers to attending a pro bono clinic is access to transportation, which was found to be a perceived barrier to care during 2017 focus groups conducted at eight locations across St. Johns County. According to the community health assessment, only $4 \%$ of St. Johns County residents do not have access to a vehicle, and only $0.2 \%$ use public transportation as a primary form of community mobility (St. Johns County 
Health Leadership Council, 2019). However, the document noted that the elderly population in the community had a disproportionate disadvantage regarding transportation challenges. Public transportation in the local area was a focus area of improvement, as access to public transit was not easily accessible for many (St. Johns County Health Leadership Council, 2019).

Below are the most recent community health objectives for St. Johns County.

\section{Table 2}

2018-2020 Strategic Objectives for St. Johns County, FL

\begin{tabular}{|c|c|}
\hline Community Health Priorities & Strategic Objectives \\
\hline $\begin{array}{c}\text { Community Assets } \\
1.0\end{array}$ & $\begin{array}{l}\text { Increase access to transportation } \\
\text { Increase resources for community health improvement } \\
\text { Assure linkage to care }\end{array}$ \\
\hline $\begin{array}{l}\text { Community Learning \& Planning } \\
\mathbf{2 . 0}\end{array}$ & $\begin{array}{l}\text { Improve community livability to address social } \\
\text { determinants of health } \\
\text { Protect population from emerging health threats } \\
\text { Improve child safety and well-being }\end{array}$ \\
\hline $\begin{array}{c}\text { Community Implementation } \\
\mathbf{3 . 0}\end{array}$ & $\begin{array}{l}\text { Reduce Risky Behaviors } \\
\text { Increase access to dental care } \\
\text { Increase access to mental health care } \\
\text { Improve overall health outcomes }\end{array}$ \\
\hline $\begin{array}{l}\text { Community Health Status } \\
4.0\end{array}$ & $\begin{array}{l}\text { Reduce chronic disease and related health inequities } \\
\text { Reduce communicable disease incidence } \\
\text { Reduce Crime \& injury }\end{array}$ \\
\hline
\end{tabular}

Note. Reprinted from the "2017 Community Health Assessment”, by the St. Johns County Health Leadership Council, 2019, p.120. Retrieved from http://stjohns.floridahealth.gov/programs-andservices/community-health-planning-and-statistics/community-health-assessments/2017cha.html

After reviewing this data and speaking with representatives from community organizations, it was determined that the USAHS pro bono clinic aligned well with the strategic objectives for St. Johns County. The clinic provided an additional community health resource that complements the goal of reducing the impact and inequities of those with chronic diseases. There are resources available through community organizations aimed at decreasing inequalities 
and improving the physical and mental health of citizens. Still, there is minimal access to occupational or physical therapy services outside of the traditional channels. Stakeholders from local organizations expressed their support of continued operations and increased awareness of the USAHS clinic, which is a great resource to the underserved.

\section{Student Needs Assessment}

When considering the potential impact of a university-sponsored pro bono clinic, the needs of students are equally important as those of patients. These needs were assessed by conducting several focus groups, which included OT students from three different terms in the curriculum, following the guidelines for conducting focus groups outlined by Doody, Slevin, and Taggart (2013) and by Harrell and Bradley (2009). These groups were held both before and after participating in the clinic. This format allowed for the evaluation of both the student needs and their perceptions on the effectiveness of the pro bono clinic in meeting those needs.

At the beginning of this project, clinic operations had just ended for the term, with the current cohort of fourth term OT students finishing their rotations. A 30-minute focus group was conducted with these students in a classroom with no faculty members present. The entire cohort was invited to voluntarily participate in the group, resulting in a group of 38 students. The goal of this group was to identify strengths and opportunities that could be addressed prior to the clinic beginning the following term. Understanding the unmet needs of these students provided early insight into areas of clinic operations that needed to be addressed.

Several themes emerged during the focus group. The majority of students agreed that participating in the clinic had a positive impact on their clinical and documentation skills. Students appreciated faculty oversight but expressed a desire for increased feedback on their performance. Students reported that they would have liked an introduction to the program earlier 
in the curriculum and more time in the clinic, as they only participated for one week. One student described her experience: "It was awesome working with real clients, but only spending two days in the clinic was not enough". Students also felt that a skill "boot camp" at the beginning of the term could have increased their readiness for the clinic. The skills that were mentioned included a general orientation to pro bono clinic, conducting initial evaluation and reevaluations, and documentation practices. Lastly, students requested a solution for client cancellations, which they felt took away from their experience.

Assessing the needs of students continued into the following term. Each rotation consisted of eight student therapists participating for two weeks. The final two weeks, which were cancelled due to the Coronavirus (COVID-19), were to be reserved for volunteers and students needing additional experience due to faculty concerns with their initial performance. Before the beginning of each rotation, a voluntary focus group took place in an empty classroom with no faculty members present. The objective of these groups was to receive candid answers regarding feelings toward, and expectations of, participating in the clinic, which may have been skewed if faculty members were involved. There was also a group conducted with 12 clinic volunteers, who were in either their second or third term of the OT curriculum.

The three focus groups with incoming rotations of student therapists had an average of eight participants. An overarching theme in each of these groups was anxiety about working in the clinic. For most students, this experience marked their first time interacting with real clients acting in the role of an OT. Regarding preparedness, one student stated, 'I just don't feel ready. I'm scared that I will mess up". This sentiment was echoed by other participants, many of whom also reported not feeling that they possessed the clinical skills necessary to treat actual clients. The most common expectations of clinic participation were to receive mentorship during the 
experience and to feel more prepared for Level II fieldwork after their rotation. Outside of treating clients, the majority of students were most concerned about documentation practices. While different components of documentation are taught during the curriculum, students are required to complete full evaluation and treatment notes on their pro bono clients, which some students did not feel confident in doing. The area of greatest self-efficacy among the groups was soft skills, as most students felt that they would be able to communicate effectively with clients.

As a part of an initiative to increase student involvement in the clinic, positions were created for students from earlier terms in the curriculum. Prior to the start of pro bono operations, a focus group was conducted with 12 second term students who volunteered for these positions. The students in this group also reported feeling anxious about participating in the clinic. One stated: "I know it's a long way off, but I am already nervous about working with clients in pro bono." The majority of students reported that they had volunteered so that they could be introduced to the clinic before their fourth term, which they hoped would ease their fears about the pro bono rotations. Another common theme was a desire to improve soft skills, with the expectation that the experience would afford them opportunities to interact with clients.

\section{Creating a Mission and Vision}

To create a mission and vision statement for the pro bono clinic, it was important to consider the USAHS mission, as the clinic mission should align with that of the University. The identified needs of the community and students were also factored into the process, as these groups are the primary beneficiaries of clinic participation. The other consideration was the value proposed by other community programs. Therefore, a search of area organizations was performed to gain an understanding of their goals for helping the underserved in the community. Each of these organizations, either directly or indirectly, provided access to services, positively 
impacting public health and engagement in occupations. Local organizations that were contacted during the planning phases of the USAHS clinic include the Wildflower Clinic, St. Johns County Veteran Affairs Health Clinic, Flagler Hospital, St. Johns County Council on Aging, and St. Johns County Department of Social Services.

After considering the needs of the underserved and students, the mission of the USAHS and other community programs, and the feedback from faculty, the mission and vision for the pro bono clinic were drafted. The objective was to capture the benefits to both the community and the students, as well as the intersection between the two. According to Palombaro et al. (2011), aligning the mission and vision of the program with those of the university is essential and helps with developing clinic objectives and a strategic plan.

Mission: The University of St. Augustine College of Health Science Pro Bono Clinic's mission is to provide professional, high-quality, client-centered physical and occupational therapy services to the underserved, uninsured, and underinsured community members in St. Augustine and surrounding areas.

Vision: The University of St. Augustine College of Health Sciences pro bono clinic vision is to provide innovative education to future clinical therapists while increasing access to engagement in meaningful activities by providing client-based innovative therapeutic interventions dedicated to improving the physical, mental, and social health of our community.

\section{Investigation of Best Practices}

An objective of this capstone project was to make contact with leaders from 2-3 universities that offer pro bono OT services. The USAHS pro bono clinic offers both OT and PT services, and so the search included schools with an interprofessional focus. Representatives from three such programs were contacted. Each agreed to participate in a one-hour interview to 
discuss best practices for clinic operations and sustainability. These interviews were conducted after completion of the needs assessment and development of the clinic mission and vision to ensure the foundation was based on the needs of students and the local community. Although these universities were instrumental in the development of comprehensive policies and procedures, it was essential that the mission and vision of the USAHS clinic aligned with that of the university and were free from the influence of other programs.

The interviews were conducted over the phone, as face-to-face interviews were not feasible due to distance. The format of the interviews was semi-structured, with the lead OTR of the USAHS pro bono clinic present to assist with questioning and transcription of critical points. The interview questions were designed to address both the barriers to sustainability noted through the literature review, as well as the weaknesses and opportunities identified during the initial SWOT analysis (see Appendix A). The interviews elicited policies and procedures that have been effective in clinic operations, barriers to sustainability, and strategies employed to mitigate those barriers.

A common theme related to the viability of a clinic included the use of a university lab or classroom space to host operations. Many pro bono clinics, including each of these programs, relied on external funding sources and donations for startup and maintaining operations, and so utilizing campus space was important to keep overhead costs to a minimum. Established marketing channels included advertising through the university, community partners, and social media. Each of these mediums were used to generate patient referrals. One university representative reported that their clinic saw neurological and orthopedic clients and that they marketed solely through the university-affiliated clinic. "While we typically have a waitlist for neuro patients", she explained, "we often have challenges getting enough orthopedic patients". 
A theme that was highlighted by all university representatives was the importance of including students in the planning and execution of a pro bono clinic. Each program had an element of student leadership, with students applying and interviewing for various roles related to the business operations of the clinic. One clinic founder reported advocating for students to take as much responsibility as possible, stating, "when starting the clinic, I had the students help write the policies and procedures. They have been involved since the beginning”. While one university reported the clinic was run exclusively by students, the best-organized program utilized a small faculty board to provide oversight and mentorship to the student leaders. This oversight allowed the faculty to ensure sound decision making that aligned with the mission and objectives of the clinic. By shifting clinic responsibilities to students, the faculty reported feeling that less burden was placed on them, making continued operations more sustainable.

University leaders also agreed that interprofessional experiences were a benefit of clinics that offered both OT and PT. Still, none had formal policies in place to foster a relationship between the professions. One representative reported holding a grand round meeting before each clinic, which he found helped to bridge the professions and encourage interprofessional collaboration. Another practice was to include PT and OT students on the leadership board, which used a top-down approach to promote interprofessional decision making.

An important practice for the programs with shared student and faculty leadership structures was to maintain a small student to therapist ratio. One instructor per two students was found to be beneficial, with one leader stating it "helps ensure students get the best educational experience and patients get the best care possible". Limiting the number of students that one instructor supervises increased his or her ability to provide oversight and mentorship. One of the 
primary objectives of each clinic was to nurture an optimal learning environment, which was better accomplished by maintaining a close student-faculty relationship.

\section{Student Leadership Development}

Each of the universities contacted during this capstone included an element of student leadership, which is consistent with a review of the literature (George et al., 2017; Palombaro et al., 2011). Student management in pro bono clinics has been shown to positively impact skills such as leadership, teamwork, marketing, and communication (Wilson \& Collins, 2006). The student board is typically a formal organizational structure, with conventional roles including clinic coordinator, student scheduler, outcomes coordinator, operations coordinator, and marketing/community relations officer. Depicted in Figure 1 below is an example of a clinic organizational chart, developed by Widener University. This model was used as a reference for the creation of a student board by one of the programs interviewed during this capstone project.

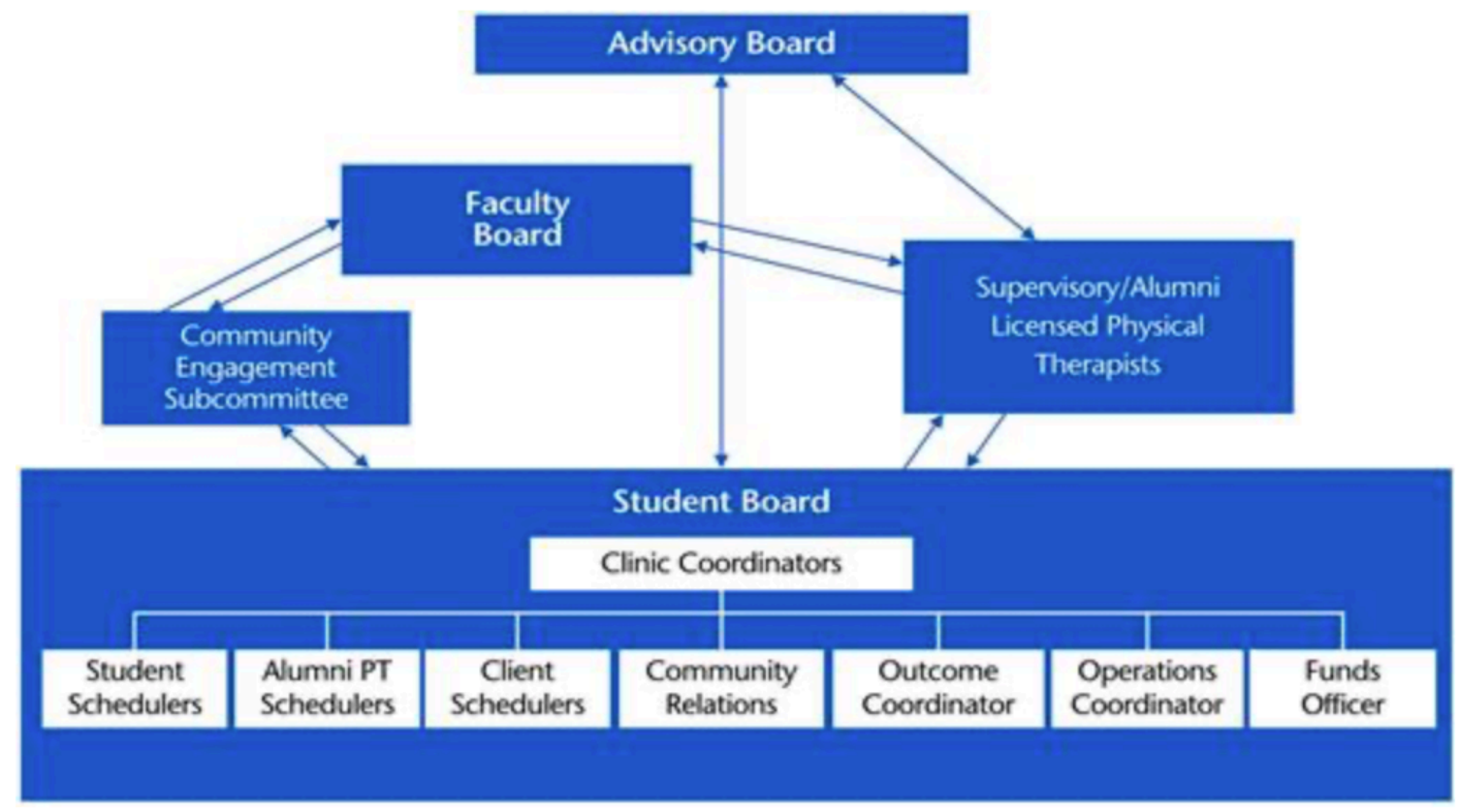

Figure 1. Clinic Organizational Chart. Reprinted from "Student experiences in creating and launching a student-led physical therapy pro bono clinic: A qualitative investigation”, by 
J. Black, K. Palombaro, and R. Dole, 2013, Physical Therapy, 93(5), p.639.

At the onset of this capstone project, there was no student involvement in the USAHS pro bono clinic. Interviews with faculty members revealed that there were concerns about allowing students to have control over business operations, leaving the lead faculty members to conduct all aspects of running a non-profit community clinic. One instructor reported that "trying to run the pro bono clinic in addition to my faculty position is extremely exhausting". Faculty also voiced concerns about placing too much responsibility on students, who are often extremely busy with the academic curriculum.

While faculty members were hesitant to allow student involvement in the clinic, two leadership roles were agreed upon for implementation into the clinic. These positions were designed to manage the new volunteer opportunities and were filled by two high performing second term students that were approved by faculty leaders. A client liaison position was established, who was placed in charge of scheduling and overseeing volunteers for a meet and greet station. Personnel assigned to this station were responsible for setting up check-in and waiting areas, providing clients with building access, and escorting them to the waiting area. The second position created was used to facilitate scheduling and oversight of the rehabilitation tech volunteers, who were tasked with setting up the clinic and providing assistance to student therapists during treatments.

The student leaders agreed to hold their positions for two consecutive terms, with the goal of creating a mentorship program whereby the leader of each position would spend their second term training their successor. This process would not only add additional layers to the leadership experience but would also result in greater consistency of operations each term. The student leaders were charged with drafting a document outlining the roles and responsibilities of 
their respective positions. These roles were modified during the term as a part of the continuous quality improvement initiative, and ultimately were added to the SOP manual. As an incentive for taking on these roles, each student was credited with professional development hours for their participation and received a letter of recommendation from the lead faculty member.

Feedback from the students regarding their involvement was positive. They reported feeling that they had gained confidence in their leadership, communication, and administrative abilities. "I think I am more prepared to lead others in the future after this experience", one student stated. The lead OT faculty member was also satisfied with their involvement, which she reported gave her more time to focus on the broader mission of the USAHS pro bono clinic. Both the students and the faculty supported expanding the breadth of leadership opportunities.

\section{SOP Development}

Before the onset of clinic operations, several changes were implemented based on results from the needs assessments, interviews with other programs, and feedback regarding previous terms of pro bono clinic operations. The EMR system being used by PT was introduced to OT, allowing the two professions to use the same documentation system and reducing the administrative burden on faculty of reviewing and maintaining physical records. Previous students reported that one week was not sufficient time in the clinic, and so participation was increased to two weeks to allow students to more fully realize the benefits of the experience. A pre-brief was conducted with each rotation of students to familiarize them with the clinic and its expectations, as well as to review potential assessments and treatments based on the common client conditions seen in the clinic. Two-hour open lab sessions were offered weekly by OT faculty. These allowed students more time to discuss client treatment plans and to practice assessments and interventions. 
A rough draft of the SOP was created using input from faculty, incoming students, and former pro bono participants. Best practices of other programs were also utilized in the development of the SOP, helping to create an initial framework for consistent and efficient operations. Policies and procedures were added and revised during the course of the term, with a mindset of continuous quality improvement encouraged for all stakeholders. Regular meetings were held with both OT and PT faculty to solicit feedback and work through operational challenges. Student therapists and volunteers were encouraged to participate in the improvement process, allowing them to take ownership in the development of the clinic manual.

The pro bono clinic was open for six weeks during this capstone project. There were several notable policies developed throughout the duration of the clinic. Policies were created and refined to ensure consistent clinic set up, referral handling, client scheduling, documentation, and professional behaviors. A policy was developed requiring student therapists to call their clients with appointment reminders. Feedback from clients indicated that this client-centered reminder did help deter them from missing appointments, reducing the impact of client "noshows" on the clinic's efforts.

One of the primary objectives for the pro bono clinic was to encourage collaboration between OT and PT student therapists. To successfully fulfill the pro bono requirements, students had to engage in at least one interprofessional interaction, either a co-evaluation or cotreatment. Further, a policy was enacted to encourage students to pair with a student from the other profession when they had openings in their schedules. This policy was found to be very helpful in promoting interprofessional experiences and allowed students to educate one another on their respective roles as it related to individual clients and their conditions. 
Another policy was developed to support a proper client transition during the change in student rotations. It was discovered during the literature review that clients commonly feel that they are passed between student therapists with little care given to the changeover. By overlapping rotations for one day, outgoing students were able to introduce their replacement, minimizing the disruption in client rapport and progress towards the treatment plan. A grand round meeting was held with both rotations and faculty to discuss the client caseload, further ensuring continuity of care.

\section{Assessing Effectiveness}

This capstone was approached with the mindset of inclusion and continuous quality improvement. It was essential to engage and include all stakeholders throughout the process to ensure a foundation for a sustainable community program. Several methods were used to solicit feedback, such as client interviews, meetings with faculty, and focus groups with students. These interactions were instrumental in understanding the needs of stakeholders and in designing the pro bono mission, objectives, policies, and procedures. Ideas for process development and improvement were encouraged from all stakeholders, helping to create sustainable policies that increased the efficiency and enhanced the pro bono experience.

Informal client interviews were conducted during clinic operations, with an emphasis on clients who had participated in multiple pro bono terms. Several repeat clients that had been seen by both PT and OT provided voluntary feedback to this researcher regarding their experiences. The objective of these engagements was to understand the client's perceptions of the clinic flow, including the scheduling, appointment reminder, check-in, treatment, and discharge processes. They were also encouraged to share any ideas on how the clinic operations could be improved. 
Clients were generally pleased with the pro bono experience. The clients enjoyed the personal contact from their student therapist regarding scheduling and appointment reminders, with one client stating, "it really makes me feel like my therapist cares about me". Clients commended the faculty on the oversight provided to the student therapists throughout the process, which they felt helped with both the administrative efficiency and quality of care they received. A client that had been seen the previous term by both PT and OT stated, "it seems like the communication is getting better between these guys; I have seen them talking, and they both seem to know what's going on with me". One client reported that "each term the clinic seems to run a little smoother. My only negative comments are that the clinic area gets really crowded and there is not much privacy". Common complaints included the waitlist for PT services and the hours of availability, with one client stating, "it's hard for someone who works to come in during the middle of the day".

Faculty members were mostly positive about the clinic operations. One faculty member reported, "this is the smoothest term we've ever had in pro bono". The lead faculty members from both OT and PT were very engaged in process improvement, leading to many positive changes throughout the term. There were some inconsistencies with the process of handling referrals, which was attributed to not having an interprofessional means of deciding which profession should see each client. External referrals were routed through the PT faculty administrative assistant down through the PT faculty members, so the OT team did not always get to screen the referrals. The implementation of EMR for OT initially presented some challenges, which was aided by the development of standardized documentation procedures. By providing video tutorials and a checklist, students had a reference for note writing, and faculty had procedures for signing off on notes. 
After completing their two-week clinic rotation, each group of student therapists was invited to participate in a voluntary focus group. Of these three cohorts, all who had attended the group before their rotation agreed to participate. Feedback regarding the experience was overwhelmingly positive. Students enjoyed the increase of clinic time to two weeks, which they felt gave them enough time to become comfortable, build rapport with their clients, and gain valuable clinical experience. The increase in interprofessional opportunities was well-received, with one student stating, "I have a much better understanding of not only what PT does, but how we can work together to treat a client". The students appreciated being responsible for the scheduling and appointment reminders of their clients, which they felt was an opportunity to improve upon their communication skills. The first group of students had negative feedback regarding the user-friendliness of the EMR, which prompted further policy development for client documentation. Opinions regarding electronic documentation improved over the term, with the final group reporting little difficulty with navigating the system.

Student volunteers in their second semester of the OT curriculum also participated in interviews throughout the term. These students, who occupied the newly formed positions of meet and greet staff and rehabilitation technicians, provided valuable input that helped to further define the role responsibilities. The meet and greet volunteers appreciated the interaction with clients, but some felt that they did not get much experience inside the clinic. One student stated, "sitting out front and escorting clients back was a good way to work on my soft skills, but it did not help alleviate my anxiety about my pro bono rotation”. Many of the rehabilitation technicians, who assisted student therapists during client treatments, felt that the experience made them much more confident in future clinic participation. These students were allowed to float throughout the clinic, assisting both OT and PT student therapists as necessary. "While I 
wasn't sure about the lack of structure", one student stated, "it ended up giving me a chance to bounce around and see a lot of different conditions".

\section{Limitations}

Although there were many strengths and valuable information identified in the community needs assessment, there were several limitations to conducting a thorough and reliable evaluation. According to the CDC (2013), a team of community representatives should be assembled, who then orchestrates the data collection related to the objectives of the needs assessment. A best practice is to collect data over a period of time using methods such as focus groups, surveys, and individual interviews of community members. Due to the nature of this capstone project, the assessment was conducted by one student in a short time, using available resources and individual interviews with stakeholders from community-based organizations. Collecting data using these methods may not be representative of the community, as they are based on a small sample size. Additionally, the individuals interviewed from various organizations may have biased opinions, so objective data was utilized whenever possible.

This project was also limited by the short time frame to evaluate clinic operations. The clinic was only operational for two hours, two days a week, for six weeks during the project time frame. The clinic was initially scheduled to be open for nine weeks but was forced to cease operations early due to health concerns related to the global outbreak of COVID-19. The abrupt halt to clinic operations shortened the planned time frame for process improvement and limited the amount of client feedback collected.

The project outcomes were based on evaluating one geographical area and using the operations of one facility to derive a sustainability model for large scale implementation. This area of operation may not be representative of every university. There was no transportation 
provided for clients, which is a known barrier to keeping appointments (Delahunt et al., 2018).

The clinic was offered during normal business hours, which may have also limited the participation of community members who were unable to take time off from work (Kamimura, Panahi, Ahmmad, Pye, \& Ashby, 2018).

Limitations were encountered during the development of a clinic-wide SOP, resulting in several policies that differed between OT and PT. The variance in operational procedures was due to deep-seated beliefs that were inconsistent between the professions, a limitation that was difficult to overcome in a short time. The two professions began offering pro bono services during different terms, with each creating informal policies to guide operations. Trying to change perceptions on the operations and gain buy-in from all faculty members on certain policies was challenging, resulting in some complexities in the policies and procedures manual.

\section{Delimitations}

Due to the short time period of this capstone, a few decisions were made a priori to establish and maintain a narrow focus for the project. Student feedback was collected mainly through the use of focus groups rather than individual meetings. While these groups allowed for the contribution of more students, the format might have resulted in the hesitancy of some to share honest opinions that conflicted with the group consensus. Family members and caregivers were excluded from the feedback process, as client perceptions were the focus of this capstone.

\section{Conclusion}

While there were challenges experienced during the capstone process, valuable insights were gained through the completion of each project objective. Communication with clients, students, faculty, other universities, and community organizations were instrumental in successfully conducting the planning, implementation, and evaluation phases of this capstone 
project. The culmination of the information gathered during this project will improve the ability of the USAHS to sustain pro bono clinic operations moving forward. This information will also benefit other OT programs when designing and launching similar programs. 


\section{Chapter 5: Summary}

\section{Introduction}

The purpose of this capstone project was to develop a theory-based approach to implementing a sustainable OT student pro bono clinic that could be utilized by other universities. The PPM was used to provide a theory-based structure for the model, as it is a

proven approach to health program planning (Porter, 2016). This organizational approach helped to divide the components of sustainability into the various stages of program development, implementation, and evaluation. The proposed strategy was developed through a literature review, collaboration with other schools, observation of the USAHS pro bono clinic, and engagement with key stakeholders throughout the process.

When turning to the literature, the limited information specific to OT is based on starting pediatric pro bono clinics (Gaffney, 2019; Zachry et al., 2016). Gaffney (2019) outlined 12 steps taken when starting a pediatric OT clinic at Gannon University, but the start-up guidelines were written from a logistical perspective, with little mention of program sustainability. One model that was of particular help was developed by Palombaro et al. (2011) through planning and implementing a student-led PT pro bono clinic at Widener University. This model focused on sustainability and was evaluated against the eight strategies for creating sustainable community initiatives by Smith et al. (2006). One of the programs interviewed during this capstone project reported successfully planning and implementing a student-led clinic offering PT and OT services using the model from Widener University to guide the process. The best practices learned through the literature review and from collaboration with other programs formed the basis for an OT-specific model. 


\section{Planning for Sustainability}

Proper program planning is essential to developing a sustainable student pro bono clinic. Preparation occurs during the PRECEDE phases and finishes with the program implementation. Considering the USAHS clinic was operational prior to this capstone project, many of these steps had already been executed. Looking retrospectively at the planning process, however, allowed for the comparison of the USAHS program against models identified in the literature review and the experience of other universities that had started similar programs.

Central to planning any community program is to understand what the target audience needs and what can be done to meet those needs (Li et al., 2009). Therefore, the first step should be identifying a target population and conducting a needs assessment. In the case of an OT student pro bono clinic, it is essential to consider the unmet needs of both the community and OT students. Understanding the needs is arguably the most important component of building a sustainable program, as it sets the foundation for an organizational structure, objective development, and the anticipation of challenges. Relationships can be established with local organizations through the process of conducting a needs assessment, with the formation of genuine community partnerships increasing the likelihood of clinic sustainability (Palmobaro et al., 2011). There are many organizations that serve vulnerable populations such as the elderly, veterans, impoverished, and those with disabilities. These organizations can help to identify community needs, and serve as referral networks by connecting their clients with the clinic.

Considering the unmet needs of students is also a vital first step. The clinic structure and objectives can be carefully designed to remedy the identified deficiencies in the student experience. With proper planning student pro bono clinics can not only enhance readiness for clinical practice, but they can also provide valuable experience with interprofessional 
communication as well as with administrative and leadership skills (Black et al., 2013; Ries, 2010; Tsu et al., 2018).

Deciding on an organizational structure should also occur early in the planning process. To be considered a student-led pro bono clinic, there must be an element of student leadership. Establishing a student board not only empowers students to help design the program, but also reduces the burden of clinic operations on university faculty. Including students throughout the process helps to increase buy-in, which is an essential component of sustainability (Black et al., 2013). Having student roles such as a volunteer coordinator, client scheduler, community relations, financial manager, and administrative executive can help reduce the amount of time the faculty spends managing the clinic. Additionally, providing students with mentored leadership opportunities can help foster managerial skills that will be beneficial in their careers. Each of the successful pro bono clinics encountered during this capstone utilized direct student involvement.

While there should be an element of student leadership, there must be faculty oversight of the clinic. One university interviewed reported being entirely student-run, which resulted in poor performance of the clinic due to a lack of experience and little faculty support. A faculty board can be small, but it is necessary for sustainability. Having a faculty organizational structure places ownership on individuals for program planning and implementation. This board also delineates those charged with decision-making regarding the program.

The clinic as USAHS has been operating since its inception as a faculty organized and led program. The current structure has resulted in a select few staff members carrying the weight of the clinic each semester. Feedback received during this capstone indicates that managing a pro bono clinic while performing a full-time instructor role is tiring and would be challenging to continue long-term. Reducing the burden on the faculty also increases their availability to mentor 
student therapists, a key ingredient to realizing the benefits of a student pro bono clinic.

Therefore, implementing a combination of student leadership with faculty oversight should be considered for a sustainable program.

Along with conducting a needs assessment and determining an organizational structure, a mission and vision statement for the clinic should be established to outline the purpose, goals, and values of the program. These statements should align with those of the university and are the pillars on which the objectives and strategic plan are built (Palombaro et al., 2011). The objectives should explicitly identify how the program will meet the needs of both the community and OT students.

Once there is an understanding of unmet community and student needs, the planning process can progress. While many of the preparatory steps for the USHAS clinic were performed before this capstone project, they are essential in planning a sustainable program. Best practices for these steps are recommended based on collaboration with involved faculty at the USAHS clinic, founders of other programs, and a literature review. Critical components include procuring a clinic location, deciding on how the program will be funded, and obtaining necessary approvals (Gaffney, 2019; George et al., 2017; Palombaro et al., 2011; Rogers et al. 2017).

If available, utilizing an area already owned by the university can reduce the overhead costs associated with operating a nonprofit program. Using university space is also generally the most convenient location for students and faculty, as well as for managing equipment and supplies. If using university space is not feasible, another option is to find community organizations with extra space who are willing to host the pro bono clinic. If the goal is to provide therapy to the underserved community, as is the case with most student pro bono clinics, then access to public transportation must be considered. Lack of transportation is one of the most 
commonly reported barriers to keeping scheduled appointments, which can be a significant hindrance to program sustainability (Delahunt et al., 2018; Kamimura et al., 2018).

While the clinic at USAHS is backed primarily by the university and fundraisers by student organizations, other common financial resources to consider include grants and donations from students, alumni, faculty, and the local community. Donations of money, equipment, and supplies can help reduce the costs associated with start-up and continued operations. Consider reaching out to the community and area for-profit medical and therapy clinics, a strategy successfully used by Palombaro et al. (2011) to acquire furniture and equipment. Determining a long-term strategy for funding is vital to sustainability, and therefore should be meticulously planned before beginning a pro bono clinic.

Equally important in program planning is acquiring the necessary approvals, specifically from the university's leadership team, as well as the legal and risk management departments. Topics that should be addressed include malpractice insurance, clinic security, and appropriate marketing mediums. By hosting the USAHS pro bono clinic on campus and incorporating the experience into academic coursework, students and supervising therapists employed by the school are covered by the university liability policy. This practice was used by other programs interviewed during this capstone, as well as by Palombaro et al. (2011), who included a statement in syllabi indicating that clinic participation may be required as a part of each course. Clinic security should be discussed, ensuring the planned location offers adequate safety and security for participants. Collaborating with legal staff on program dissemination can help to build a plan that is ethical and in keeping with the values of the university. While word of mouth marketing will likely produce referrals, using community partnerships, social media, and the university network can help generate a steady source of clients. 
To complete the final step of the PRECEDE portion of PPM, all of the needs assessments conducted and information gathered should be used to confirm the mission and vision of the clinic align with the objectives of the program. The newly formed student and faculty boards should collaborate to create a comprehensive policies and procedures manual, which is critical to ensuring consistent operations and guiding the clinic towards its vision. The manual should highlight the clinic's mission, vision, and objectives (Gaffney, 2019). It should include policies and procedures related to HIPAA compliance, processing referrals, scheduling and appointment reminders, documentation, discharge, as well as the clinical and professional expectations for students and supervising therapists. New policies can be added based on the needs identified key stakeholders of the clinic. The manual should remain a living document that is revised and updated to reflect quality improvement and process efficiency efforts.

After the aforementioned steps are completed, program marketing and client scheduling can begin. The execution of the program planning efforts signifies the beginning of the PROCEED phases. During these stages the emphasis is placed not only on program implementation, but also on continuous quality improvement (Green \& Kreuter, 1999). Starting small, a strategy commonly used in business, is an excellent way to identify the strengths and improve upon weaknesses before scaling up the volume of clients (Smith et al., 2006). Commencing the program on a lesser scale allows greater flexibility in the ability to adjust components of the plan as necessary to improve the flow and experience for clients, students, and faculty. The OT clinic at the USAHS recruited eight volunteer student therapists to participate in the first semester of operations, allowing for process improvement to occur prior to requiring the participation of all students the following semester. If starting small, it is necessary 
to apply the same tactic to marketing efforts, as over-marketing can result in exceeding client capacity and result in a waitlist, which can damage the credibility of the program.

Evaluation of the processes should be ongoing and begin immediately after implementing the program, as a mindset of continuous quality improvement is vital to sustainability. Soliciting feedback from stakeholders is a quick and informal method of getting a pulse on various components of the clinic experience. Clients, students, and supervising therapists should be encouraged to provide constructive criticism if they feel there is something about the experience that can be improved. In some cases, minor process changes can improve the client or student flow. Flexibility is a hallmark of the PPM, and it should be applied to process improvement (Green \& Kreuter, 1999).

While some processes might benefit from changes in real-time, most should be evaluated using a more structured approach. Phases 5-8 of the PPM focus on the evaluation of the process, impact, and outcomes of the program (Morris \& Jenkins, 2018). The use of student focus groups proved to be valuable for process evaluation and improvement during this capstone project. Once an issue has been identified, DMAIC is a useful problem-solving approach for targeting process variation and efficiency: Use of DMAIC has been shown to reduce client cycle time by $20 \%$ in nonprofit health care clinics (Kovach \& Ingle, 2019).

Student and client surveys are also commonly used to objectify the pro bono experience and can be designed to detect problems that could jeopardize sustainability. Data collection should be used to gain insight into how well the clinic is meeting its objectives, which generally aligns with the impact evaluation phase of the PPM. If the data suggests that the clinic falls short on attaining its goals, it may signal the need for new policies or procedures. If the problem is related to an existing process, the DMAIC problem-solving approach should be utilized. 
The information collected from stakeholders should also be used to inform strategic planning for the future of the program. If a continuous quality improvement mindset is maintained and collaborative problem-solving occurs, then over time the process and impact evaluations should yield positive changes in the client and student experience. Selecting an appropriate client outcome measure, such as a quality of life assessment, can help determine if the program is moving towards achieving its vision. Using the results of the process, impact, and outcome evaluations to continuously build upon the strengths of the program will ultimately result in a more sustainable OT student pro bono clinic.

\section{Envisioned Next Steps}

During this capstone project, several opportunities for future research were identified. While community pro bono clinics have been shown to improve student skills and readiness for clinical rotations in other disciplines, there is little research on the impact the experience has on OT students (Black et al., 2017; Cassidy \& Yorke, 2019; Dhans et al., 2015; Palombaro et al., 2011). While feedback from interviews and focus groups indicate that improvements made in clinic operations through this capstone project will help optimize the student experience, a scientific study of the impact of the pro bono experience on students is a good topic for future exploration. Conducting a student self-assessment before and after clinic participation would allow the OT profession to gain a greater understanding of how these clinics effect critical student skills such as clinical, communication, and administrative. Conducting a study on student perceptions of the pro bono clinics' impact on readiness after completion of their first Level II fieldwork experience might provide additional insights into the effectiveness of participation in the program. 
Another area of potential exploration is the impact of the clinic on the quality of life of clients that attend. Although client impact is not the direct focus of this capstone, the pro bono clinic is intended to be a program that provides needed services to the underserved in the community. Through creating a referral network and improving client flow, there is an opportunity for steady client-centered experiences that have a positive effect on engagement and participation in meaningful occupations. Measuring the health outcomes of pro bono clients would expand the OT body of knowledge by quantifying the benefits of student-directed therapy on client quality of life and occupational engagement.

\section{Conclusion}

This capstone project was completed to provide a comprehensive, theory-based approach to starting a sustainable OT student-directed pro bono clinic. The various stages of program planning and implementation were broken down into a logical format using the PPM for community program development. Following the steps put forth by this model ensured that the foundation of the clinic accurately reflected the needs of students and the community. Consideration of the needs assessment data along with the goals of the university and best practices identified through collaboration with similar programs allowed for informed planning of the clinic objectives, structure, and procedures. Open communication and the inclusion of all stakeholders was encouraged throughout the planning and implementation stages, resulting in a

more efficient clinic and enhanced experience for all involved. Conducting a SWOT analysis and developing a strategic plan will ensure a sustainable pro bono clinic at the USAHS that continues striving to reach its vision.

Student-directed pro bono clinics offer an experiential learning opportunity that can improve student self-confidence in their clinical skills and readiness for Level II fieldwork 
(Black et al., 2017; Cassidy \& Yorke, 2019; Dhans et al., 2015; Palombaro et al., 2011). These programs can be implemented into the OT course curriculum and provide the university with an innovative and realistic method of conducting Level I fieldwork hours while under the mentorship of faculty. Offering care to the local community also demonstrates the AOTA core values of altruism and justice, exposing students to the importance of serving the underserved.

While there were unique challenges associated with the complexities of the clinic at the USAHS, the information resulting from this capstone can serve as a guide for other universities when planning and operating similar programs. After researching the use of student clinics in other healthcare disciplines and learning from the experiences of other universities, this model was tailored to the occupational therapy profession. By planning for sustainability from the onset, universities will be better equipped for the long-term realization of the benefits of an OT student pro bono clinic. 


\section{References}

Andonian, L. (2017). Occupational therapy students' self-efficacy, experience of supervision, and perception of meaningfulness of Level II fieldwork. Open Journal of Occupational Therapy (OJOT), 5(2), 1-12. doi:10.15453/2168-6408.1220

Azar, F. E., Solhi, M., Nejhaddadgar, N., \& Amani, F. (2017). The effect of intervention using the PRECEDE-PROCEED model based on quality of life in diabetic patients. Electronic physician, 9(8), 5024. doi:10.19082/5024

Baxter, S., Killoran, A., Kelly, M. P., \& Goyder, E. (2010). Synthesizing diverse evidence: the use of primary qualitative data analysis methods and logic models in public health reviews. Public health, 124(2), 99-106.

Bennett, S., Rodger, S., Fitzgerald, C., \& Gibson, L. (2017). Simulation in occupational therapy curricula: A literature review. Australian Occupational Therapy Journal, (4), 314. doi:10.1111/1440-1630.12372

Black, J. D., Palombaro, K. M., \& Dole, R. L. (2013). Student experiences in creating and launching a student-led physical therapy pro bono clinic: A qualitative investigation. Physical Therapy, 93(5), 637-648. Retrieved from http://search.ebscohost.com/login.aspx?direct=true \&db=s3h\&AN=87371449\&site=edslive

Black, J. D., Bauer, K., Spano, G., Voelkel, S., \& Palombaro, K. (2017). Grand rounds: A method for improving student learning and client care continuity in a student-run physical therapy pro bono clinic. Journal of the Scholarship of Teaching and Learning, 17(3), 6888. doi:10.14434/v17i3.21158 
Blayney D. W. (2008). Strengths, weaknesses, opportunities, and threats. Journal of Oncology Practice, 4(2), 53. doi:10.1200/JOP.0820501

Braveman, B., \& Bass-Haugen, J. D. (2009). From the desks of the guest editors-Social justice and health disparities: An evolving discourse in occupational therapy research and intervention. American Journal of Occupational Therapy, 63, 7-12.

Braveman, B., \& Suarez-Balcazar, Y. (2009). Social justice and resource utilization in a community-based organization: A case illustration of the role of the occupational therapist. American Journal of Occupational Therapy, 63, 13-23.

Business Plan. (2019). Retrieved from https://www.lexico.com/en/definition/business_plan

Calano, B. J. D., Cacal, M. J. B., Cal, C. B., Calletor, K. P., Guce, F. I. C. C., Bongar, M. V. V., \& Macindo, J. R. B. (2019). Effectiveness of a community-based health programme on the blood pressure control, adherence and knowledge of adults with hypertension: A PRECEDE-PROCEED model approach. Journal of Clinical Nursing, (9-10), 1879. doi:10.1111/jocn.14787

Campbell, M. K., Corpus, K., Wussow, T. M., Plummer, T., Gibbs, D., \& Hix, S. (2015).

Fieldwork educators' perspectives: Professional behavior attributes of level II fieldwork students. Open Journal of Occupational Therapy (OJOT), 3(4), 1-13. doi:10.15453/2168-6408.1146

Carvalho, E., Bettger, J. P., \& Goode, A. P. (2017). Insurance coverage, costs, and barriers to care for outpatient musculoskeletal therapy and rehabilitation services. North Carolina Medical Journal, 78(5), 312. Retrieved from http://search.ebscohost.com/login.aspx?direct=true \&db=edo\&AN=125573197\&site=edslive 
Cassidy, A., \& Yorke, A. (2019). Investigating the motivators, barriers and facilitators to volunteering at a student-run physical therapy clinic. Journal of Student-Run Clinics, $5(1)$.

Centers for Disease Control and Prevention. (2013). Community needs assessment [PDF file]. Retrieved from https://www.cdc.gov/globalhealth/healthprotection/fetp/training_modules/15/communityneeds_pw_final_9252013.pdf

Choi, K., Park, J.-H., \& Cheong, H.-K. (2013). Prevalence of musculoskeletal symptoms related with activities of daily living and contributing factors in Korean adults. Journal of Preventive Medicine \& Public Health, 46(1), 39-49. doi:10.3961/jpmph.2013.46.1.39

Collins, S., Bhupal, H., \& Doty, M. (2019). Health insurance coverage eight years after the ACA: Fewer uninsured Americans and shorter coverage gaps, but more underinsured. Retrieved from https://www.commonwealthfund.org/publications/issuebriefs/2019/feb/health-insurance-coverage-eight-years-after-aca

Creation of SSRFC. (n.d.) Retrieved from https://www.studentrunfreeclinics.org/about/

Delahunt, J. Z., Wisdom, C. M., Swift, M., \& Siscos, M. (2018). A pro-bono therapy clinic: Valuable and viable? Journal of Case Studies, (3), 6. Retrieved from http://search.ebscohost.com/login.aspx?direct=true \&db=edsgao\&AN=edsgcl.59789 $5513 \&$ site $=$ eds-live

Dhans, L., Anson, C., Callahan, K., Coats, E., Slaughter, L., Coker-Bolt, P., \& Velozo, C. (2015). Student-run free therapy clinics: Integrating service learning and care for uninsured clients. OT Practice, 20(2), 16-18. Retrieved from https://search.proquest.com/docview/1653077695?accountid=158603 
Doody, O., Slevin, E., \& Taggart, L. (2013). Preparing for and conducting focus groups in nursing research: part 2. British Journal of Nursing, 22(3), 170-173. Retrieved from http://search.ebscohost.com/login.aspx?direct=true\&db=ccm\&AN=104236561\&site=eds -live

Doucet, B. M., \& Seale, J. (2012). The free post-stroke clinic: A successful teaching and learning model. Journal of Allied Health, 41(4), 162-169. Retrieved from http://search.ebscohost.com/login.aspx?direct=true \&db=ccm\&AN=108090050\&site=eds -live

Evenson, M., Roberts, M., Kaldenberg, J., Barnes, M., \& Ozelie, R. (2015). National survey of fieldwork educators: Implications for occupational therapy education. American Journal of Occupational Therapy, 69(Supplement 2), 1-5.

Fröberg, M., Leanderson, C., Fläckman, B., Hedman-Lagerlöf, E., Björklund, K., Nilsson, G. H., $\&$ Stenfors, T. (2018). Experiences of a student-run clinic in primary care: a mixedmethod study with students, patients and supervisors. Scandinavian Journal of Primary Health Care, 36(1), 36-46. doi:10.1080/02813432.2018.1426143

Gaffney, J. (2019). Steps to opening a student-run pro bono clinic at your school. Retrieved from https://www.aota.org/Education-Careers/Students/Pulse/Archive/student-leadershipadvocacy/Clinic.aspx

George, L., Bemenderfer, S., Cappel, M., Goncalves, K., Hornstein, M., Savage, C., ... Loghmani, M. T. (2017). A model for providing free patient care and integrating student learning and professional development in an interprofessional student-led clinic. Journal of Physical Therapy Education (American Physical Therapy Association, Education Section), 31(2), 54-66. doi:10.1097/00001416-201731020-00007 
Gertz A, Frank S, \& Blixen C. (2011). A survey of patients and providers at free clinics across the united states. Journal of Community Health, 36(1), 83-93. doi:10.1007/s10900-0109286-X

Gielen, A. C., McDonald, E. M., Gary, T. L., \& Bone, L. R. (2008). Using the precede-proceed model to apply health behavior theories. Health Behavior and Health Education: Theory, Research, and Practice, 4, 407-29.

Green, L., \& Kreuter, M. (1999). The precede-proceed model. Health promotion planning: an educational approach. 3rd ed. Mountain View (CA): Mayfield Publishing Company, 3243.

Hamilton, A., Copley, J., Thomas, Y., Edwards, A., Broadbridge, J., Bonassi, M., ... Newton, J. (2015). Responding to the growing demand for practice education: Are we building sustainable solutions? Australian Occupational Therapy Journal, (4), 265. doi:10.1111/1440-1630.12181

Harrell, M. C., \& Bradley, M. A. (2009). Rand National Defense Research Institute, Data collection methods. Semi-structured interviews and focus groups. RAND Corporation: Santa Monica, CA.

Hewson, K., \& Friel, K. (2004). A unique preclinical experience: Concurrent mock and pro bono clinics to enhance student readiness. Journal of Physical Therapy Education (American Physical Therapy Association, Education Section), 18(1), 80. Retrieved from http://search.ebscohost.com/login.aspx?direct=true \&db=edo\&AN=14018986\&site=edslive 
Hu, T., Cox, K. A., \& Nyhof-Young, J. (2018). Investigating student perceptions at an interprofessional student-run free clinic serving marginalised populations. Journal of Interprofessional Care, 32(1), 75-79. doi:10.1080/13561820.2017.1363724

Institute for Health Metrics and Evaluation. (2016) US county profile: Saint Johns County, Florida. Retrieved from http://www.healthdata.org/sites/default/files/files/county_profiles/US/2015/County_Repo rt_Saint_Johns_County_Florida.pdf

Johnson, J. E. (1990). Developing an effective business plan. Nursing Economics, 8(3), 152-154. Retrieved from http://search.ebscohost.com/login.aspx?direct=true \&db=heh\&AN=12163698\&site=edslive

Kamimura, A., Panahi, S., Ahmmad, Z., Pye, M., \& Ashby, J. (2018). Transportation and other nonfinancial barriers among uninsured primary care patients. Health Services Research and Managerial Epidemiology, 5(1). doi:10.1177/2333392817749681

Kian, A., Zheng, J., Chan-Golston, A., Tam, A., Bhetraratana, M, Chiao-Wen, L., ... Prelip, M. (2018). Assessing quality of care through client satisfaction at an interprofessional student-run free clinic. Journal of Interprofessional Care, 32(2), 203-210. doi:10.1080/13561820.2017.1395827

Kovach, J. V., \& Ingle, D. (2019). Using Lean Six Sigma to reduce patient cycle time in a nonprofit community clinic. Quality Management in Healthcare, 28(3), 169-175.

Laureani, A., \& Antony, J. (2018). Leadership - a critical success factor for the effective implementation of Lean Six Sigma. Total Quality Management \& Business Excellence, 29(5/6), 502-523. doi:10.1080/14783363.2016.1211480 
Learn about Quality. (2020). Retrieved from https://asq.org/quality-resources/dmaic

Level I Fieldwork. (2019). Retrieved from https://www.aota.org/EducationCareers/Fieldwork/LevelI.aspx

Li, Y., Cao, J., Lin, H., Li, D., Wang, Y., \& He, J. (2009). Community health needs assessment with precede-proceed model: a mixed methods study. BMC health services research, 9(1), 181.

Milstein RL, \& Wetterhall S. (1999). Framework for program evaluation in public health. MMWR: Morbidity \& Mortality Weekly Report, 48(36), 1-8. Retrieved from http://search.ebscohost.com/login.aspx?direct=true $\& d b=c c m \& A N=107220057 \&$ site=eds -live

Morris, D., \& Jenkins, G. (2018). Preparing physical and occupational therapists to be health promotion practitioners: A call for action. International journal of environmental research and public health, 15(2), 392. doi:10.3390/ijerph15020392

O’Brien, G. (2019). Lean -- But not mean Mercy Medical takes a six sigma approach to healthcare. BusinessWest, 35(20), 29-36. Retrieved from http://search.ebscohost.com/login.aspx?direct=true \&db=heh\&AN=134140381\&site=edslive

Occupational Therapy Code of Ethics (2015). American Journal of Occupational Therapy, 69(Supplement 3). doi:10.5014/ajot.2015.696s03

Palombaro, K. M., Dole, R. L., \& Lattanzi, J. B. (2011). A case report of a student-led pro bono clinic: A proposed model for meeting student and community needs in a sustainable manner. Physical Therapy, 91(11), 1627-1635. doi:10.2522/ptj.20100437 
Phillips, E. A. (2017). Evaluation of a coaching experiential learning project on OT student abilities and perceptions. Open Journal of Occupational Therapy (OJOT), 5(1), 1-15. doi:10.15453/2168-6408.1256

Porter, C. M. (2016). Revisiting precede-proceed: A leading model for ecological and ethical health promotion. Health Education Journal, 75(6), 753-764. Retrieved from http://search.ebscohost.com/login.aspx?direct=true\&db=eric\&AN=EJ1113669\&site=edslive

Ries, E. (2010). Free to Lead. PT in Motion, 2(2), 24-29. Retrieved from http://search.ebscohost.com/login.aspx?direct=true $\& \mathrm{db}=\mathrm{s} 3 \mathrm{~h} \& \mathrm{AN}=48388056 \&$ site=edslive

Rogers, O., Heck, A., Kohnert, L., Paode, P., \& Harrell, L. (2017). Occupational therapy's role in an interprofessional student-run free clinic: Challenges and opportunities identified. Open Journal of Occupational Therapy, (3). doi:10.15453/2168-6408.1387

Rodger, S., Webb, G., Devitt, L., Gilbert, J., Wrightson, P., \& McMeeken, J. (2007). Clinical education and practice placements in the allied health professions: An international perspective. Journal of Allied Health, 37(1), 53-62. Retrieved from https://pdfs.semanticscholar.org/c3cd/364c7b20edb60646762d4b2a2a306f487751.pdf

Sandal, S., Iannuzzi, M. C., \& Knohl, S. J. (2013). Can we make grand rounds "grand" again? Journal of Graduate Medical Education, 5(4), 560-563. doi:10.4300/JGME-D-1200355.1

Seif, G., Coker-Bolt, P., Kraft, S., Gonsalves, W., Simpson, K., \& Johnson, E. (2014). The development of clinical reasoning and interprofessional behaviors: Service-learning at a 
student-run free clinic. Journal of Interprofessional Care, 28, 559-564.

doi:10.3109/13561820.2014.921899

Smith, M., Cohen, A., \& Raybuck, J. (2006). Building sustainable service-learning: the case of community-based watershed management. Journal of Contemporary Water Research and Education, 119(1), 4.

St. Johns County Health Leadership Council. (2019). 2017 community health assessment \& 2018-2020 community health improvement plan for St. Johns County, FL [PDF file]. Retrieved from http://stjohns.floridahealth.gov/programs-and-services/community-healthplanning-and-statistics/community-health-assessments/2017-cha.html

Stickler, K., Sabus, C., Gustafson, H., Kueser, M., Lavaveshkul, B., \& Denney, L. (2016). ProBono service through student-run clinics: How does physical therapy measure up? Journal of Allied Health, 45(3), 207-211. Retrieved from http://search.ebscohost.com/login.aspx?direct=true\&db=ccm\&AN=118362686\&site=eds -live

Stakeholder. (2019). Retrieved from https://www.investopedia.com/terms/s/stakeholder.asp

Tang, K. C., \& Davis, A. (1995). Critical factors in the determination of focus group size. Family practice, $12(4), 474-475$.

Tapley, H., \& Patel, R. (2016). Using the PRECEDE-PROCEED model and service-learning to teach health promotion and wellness: An innovative approach for physical therapist professional education. Journal of Physical Therapy Education (American Physical Therapy Association, Education Section), 30(1), 47-59. doi:10.1097/00001416201630010-00007 
Then, K. L., Rankin, J. A., \& Ali, E. (2014). Focus group research: What is it and how can it be used? Canadian Journal of Cardiovascular Nursing, 24(1), 16-22. Retrieved from http://search.ebscohost.com/login.aspx?direct=true \&db=ccm\&AN=104007438\&site=eds -live

Townsend, E., \& Wilcock, A. A. (2004). Occupational justice and client-centred practice: A dialogue in progress. The Canadian Journal of Occupational Therapy, 71(2), 75-87. Retrieved from https://search.proquest.com/docview/212952011?accountid=158603

Tsu, L., Buckley, K., Early, N., \& Jackowski, R. (2018). Evaluation of multidisciplinary and pharmacy-only student-run clinics on student's perceptions of interprofessional roles. Currents in Pharmacy Teaching and Learning, 10(6), 785-794. doi:10.1016/j.cptl.2018.03.018

United States Census Bureau. (2017). QuickFacts. Retrieved from https://www.census.gov/quickfacts/fact/table/flaglercountyflorida,duvalcountyflorida,put namcountyflorida,stjohnscountyflorida/HEA775218

Van Vuuren, S. (2016). Reflections on simulated learning experiences of occupational therapy students in a clinical skills unit at an institution of higher learning. South African Journal of Occupational Therapy, 46(3), 80-84. doi:10.17159/2310-3833/2016/v46n3/a13

What is Experiential Learning. (2019) Retrieved from http://www.ucdenver.edu/life/services/ExperientialLearning/about/Pages/WhatisExperien tialLearning.aspx

Wilson, J. E., \& Collins, J. E. (2006). Physical therapist student learning through authentic experiences in management: One program's interpretation of service learning. Journal of Physical Therapy Education, 20(3), 25-32. 
Zachry, A. H., Allen, K., Dickey, C., \& Moore, H. (2016). Opening a student-run pro bono occupational therapy clinic. OT Practice, 21(21), 22-24. Retrieved from https://search.proquest.com/docview/1841680028?accountid=158603 


\section{Appendix A}

\section{SWOT Analysis Pro Bono Clinic (12/2019)}

\begin{tabular}{|c|c|}
\hline \multicolumn{2}{|c|}{ INTERNAL FACTORS } \\
\hline STRENGTHS (+) & WEAKNESSES (-) \\
\hline $\begin{array}{l}\text { - Secure and consistent location for clinic } \\
\text { - ADL area allows for client-centered treatments } \\
\text { - Experience from several terms of PT services } \\
\text { - OT started small - allowed for controlled growth } \\
\text { - Financial backing from USAHS } \\
\text { - Involved faculty very supportive }\end{array}$ & $\begin{array}{l}\text { - Clinic space can be crowded and offers little privacy } \\
\text { - Only operates on Monday and Wednesday during normal business } \\
\text { hours - hard for individuals who work } \\
\text { - Marketing currently only by word-of-mouth } \\
\text { - Student therapists only participate for one week } \\
\text { - Faculty members running all operations - heavy burden }\end{array}$ \\
\hline
\end{tabular}

\section{EXTERNAL FACTORS}

OPPORIUNITIES ( + )

- Strong community support - marketing channels - COA and Flagler has strong networks to tap into

- Standardization of clinic procedures - OT and PT under one set

- Expansion of OT pro bono clinic to include adult and gerontology fieldwork for fourth term OT students

- St. Johns Care Connect will work with USAHS to establish guidelines for referring clients

- Wildflower clinic can provide MD referral for clients
- Shortage of public transportation options - using the Sunshine Bus Company can be a very long trip, and little service provided in rural areas

- Need for physician referrals to access services

- Wildflower clinic providing multidisciplinary care - longer hours and more services offered

- Faculty burnout from continuously managing clinic operations 